\title{
Experimental and Lattice Boltzmann Simulated Operation of a Copper Micro-Channel Heat Exchanger
}

\author{
Eric Borquist, Suvhashis Thapa, Leland Weiss ${ }^{\mathrm{a}}$, \\ ${ }^{a}$ Louisiana Tech University, College of Engineering and Science, P.O. Box 10348, \\ Ruston, LA 71272
}

\begin{abstract}
The inherent inefficiency of many thermodynamic processes provide ample opportunity to harvest waste energy which would otherwise be released to the surrounding environment. A micro-channel heat exchanger (MHE) is presented that optimizes efficiency of energy transference by taking advantage of high thermal conductivity with copper fabrication and two-phase flow with a working fluid. Increasing the efficiency of the MHE, capillary channels allow fluid flow throughout the MHE, removing the necessity of an external work mechanism. For a power input of $3.44 \mathrm{~W}$, the absorbed and transferred energy through the MHE was approximately $95 \%$ when working fluid was utilized, compared to $87 \%$ for the MHE with no working fluid. In addition to characterizing the MHE experimentally, internal operation was analyzed and reinforced through a lattice Boltzmann method simulation of a single micro-channel. The lattice Boltzmann method is a computationally efficient alternative for multi-phase systems, notoriously difficult systems to
\end{abstract}

Email address: lweiss@latech.edu (Leland Weiss)

$U R L:$ ww. latech.edu/ ${ }^{1 \text { weiss (Leland Weiss) }}$

Preprint submitted to Energy Conversion and Management

December 21, 2015

(C) 2016. This manuscript version is made available under the Elsevier user license http://www.elsevier.com/open-access/userlicense/1.0/ 
simulate. The overall objective was the development of a general laboratory fabrication technique that produced an effective two-phase MHE which was then experimentally characterized for device energy transference efficiency and computationally modeled, using experimental boundary conditions, for internal device operation. Using experimental and simulated methods, the copper MHE has proven a viable option for transferring low-temperature waste energy.

Keywords: Waste heat, Lattice Boltzmann, Heat exchanger, Capillary channels, Electroplating, Copper

1 1. Introduction

2 Increasing annual consumption of energy has driven researchers to ana3 lyze possibilities of waste heat scavenging for greater energy efficiency and 4 sustainability. While large scale heat integration has been studied for decades 5 in industry, the increasing miniaturization of devices and processing over the 6 past thirty years has opened new avenues for waste energy harvesting. Ther7 mal scavenging can provide power for external sensors or provide a platform 8 for structural health monitoring of systems on smaller scales. The key to tak9 ing advantage of these available harvesting possibilities explains the interest 10 in sustainable alternatives: inefficiency of existing systems.

$11 \quad$ Many standard thermodynamic cycles have low efficiencies where much of 12 the thermal energy generated is rejected to the surrounding environment [1]. 13 Harnessing the rejected thermal energy via transduction mechanisms allows 
existing physical effects to power additional systems, such as MEMS devices [2]. One such device, the micro-channel heat exchanger (MHE), uses multiple fluid-filled channels which, at reduced scales, produce effective heat and mass transfer due to dynamic boundary layers [3, 4]. Maximizing efficiency of MHEs necessitates optimizing channel fluid dynamics while minimizing thermal resistance $[3,5]$. Thermal resistance is reduced using two-phase flows and materials with high thermal conductivities $[3,5]$.

Beginning with the seminal publication by Tuckerman and Pease, microchannels have been extensively studied for their transport phenomena characteristics [6]. A decade after Tuckerman and Pease, researchers began to focus on two-phase flow initially studying heat transfer flow models, channel pressure drop, and critical heat flux [7]. Though flow regimes were varied in systematic flow reviews, fluid was pumped through the channels in forced convection flow $[8,9,10,11,12,13]$. Forced flow in the micro-channels increases the heat transfer potential; however, for low-power environments, methods must be used which maximize the capability of the solitary device $[11,14,15]$.

Applications for MHEs have ranged from electronics cooling to harnessing waste energy $[6,16]$. Recent research has explored system level waste heat energy harvesting solutions by characterizing heat transfer devices coupled with thermoelectric generators $[17,18,19,20,21,22]$. However, researchers have noted that in addition to improving the conversion efficiency of thermoelectric material itself, there is a parallel need to research and develop advanced 
associated heat exchangers $[23,24,25,26]$. In fact, researchers promote the optimization of TEG based systems rather than individual components in order to maximize the output power. The use of advanced heat transfer devices is critical to efficient TEG operation and future deployment [25]. Therefore, while researchers continue to investigate system level solutions for energy harvesting, the optimization of energy transfer via the MHE is the primary priority presented here.

Though current publications have shown developed waste heat recovery processes and techniques from multiple energy sources and industries, including automotive, engines, oil and gas, steel, and steam, focus here is on maximizing energy transfer via the MHE for any low-temperature waste heat source $[27,28,29,30,31,32,33]$. Low-temperature heat sources allow the production of power from renewable energy sources, such as solar radiation. Much of the most recent research has been facilitated by developing midto large-scale Organic Rankine Cycle (ORC) systems; however, there is still continued interest in the possibilities of micro-scale energy harvesting [34, $35,36,37,38]$.

While the characteristics of forced flow are important to the overall fundamental understanding of transport phenomena in micro-channels, the use of an external work mechanism reduces the overall efficiency of the device and increases overall expense due to additional equipment which is of vital concern for the MHE in question [39]. The incorporation of micro-channels and surface interactions promotes an economical path to fluid flow where 
the autonomous channel horizontal capillary flow provides fluid motion in the MHE [40, 41, 42]. In addition to fluid flow economy, the heat transfer requirements of the $\mathrm{MHE}$ demands choosing a substrate which meets the desired thermal conductivity.

Traditionally, the dominant platform for micro-fabrication and microscale devices has been silicon $[43,44]$. The reliance on silicon as the substrate or bulk material of fabrication is due to availability and established processing techniques $[43,44,45]$. Unfortunately, the low thermal conductivity of silicon, when compared to metals such as copper, and its fragility in wafer form demand viable alternatives for more effective and varied usage in dynamic environments [46]. Adoption of technologies on the global scale requires low-cost materials and processes which can be implemented with minimal equipment infrastructure. Mass-produced metal-based MHEs have the potential to yield mechanically robust systems, improved thermal conductivity, and allow varied usage around the world [5]. The exchanger proposed here has been designed to use micro-channels between two reservoirs, and was fabricated completely of copper via unique electrodeposition techniques.

Closed system devices can be notoriously difficult to characterize in situ without compromising the nature of the device. However, using theoretical formulas and experimental data, a simulation can be prepared which can verify system operation and provide useful insight into device operation. It is in this vein that a modified lattice Boltzmann model is presented to establish 
interior operation of the experimental MHE. The lattice Boltzmann method (LBM) performs particularly well for systems with dynamic surface interactions, including multi-phase systems, which are fundamentally difficult to model and computationally costly. The LBM provides an improved model on these constraints due to removing the explicit tracking of the moving phase interfaces [47].

Expanding on previous research and ongoing interest in small-scale heat exchangers in general, a copper-based, two-phase working fluid-filled MHE was constructed and tested. The overall device performance was analyzed via experimental characterization, however, there was parallel need to evaluate the internal operations of the device as well. Internal device performance was simulated using the LBM approach as detailed in this paper, relying heavily on the experimental boundary conditions and real device operating data. Through combination of the experimental and numerical research, the full operating characterization of the MHE was determined and the MHE suitability for waste heat recovery applications was confirmed.

As part of the experiment and fabrication effort, a method for the fabrication of the copper MHE is presented. The MHE has components as noted in Figure 1. It is designed for closed system operation whereby no external work mechanism is needed for fluid movement. Thermal and momentum transport are driven by using phase change of a working fluid. The micro-channels drive capillary action of the fluid such that the working fluid is dispersed over the heat source area, improving heat transfer to the working fluid. The boiling 


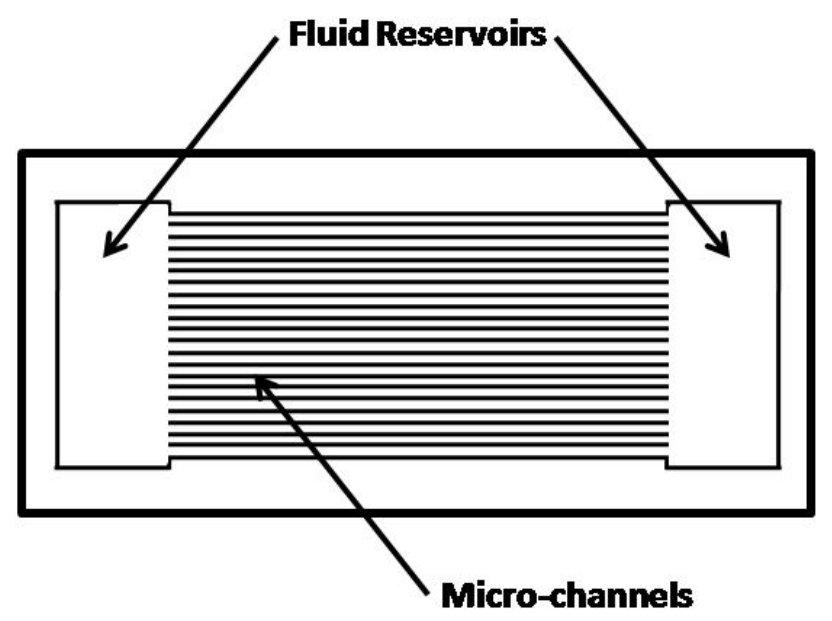

Figure 1: Components of MHE.

working fluid travels to the MHE copper lid where heat transfer to the heat sink allows condensation to occur and the working fluid returns to either the micro-channels or the reservoirs on the ends. The boiling and condensing process within the MHE is shown in Figure 2. While the MHE described is designed for multiple applications in multiple environments, the working fluid tested and modeled is specified as $3 \mathrm{M}^{\circledR}$ HFE-7200. Copper was selected for the MHE due to thermal properties; however, any metal which can be electrodeposited can be used as an alternative.

Once experimentally characterized and boundary conditions known, the LBM for a single micro-channel is developed and simulated for the working fluid phase change. Implementing the LBM scheme requires a thorough understanding of the system in question as well as the properties of the working 


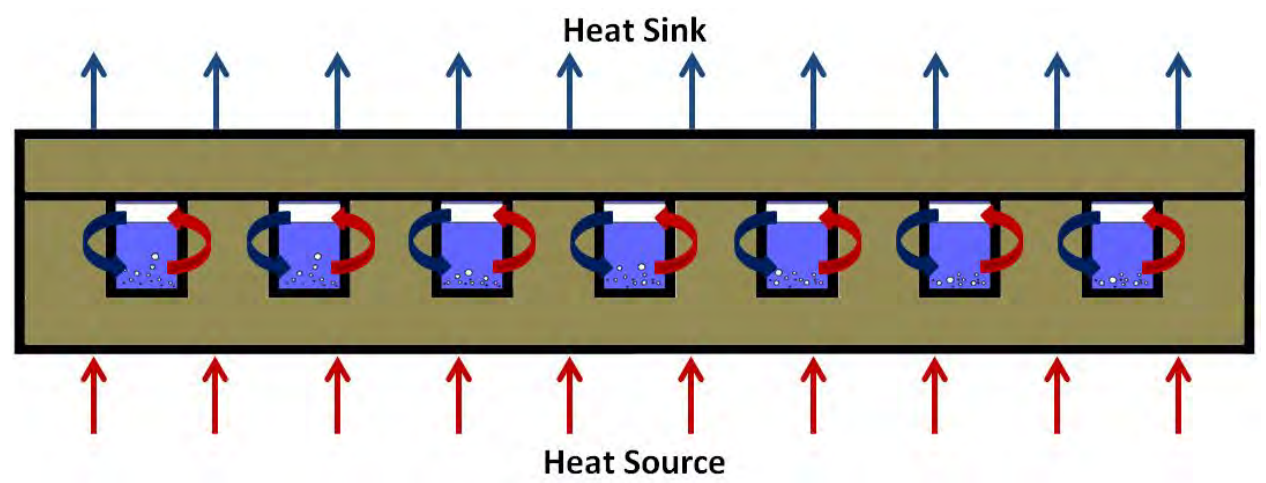

Figure 2: Fluid Cycle Interaction in the MHE, where each Channel is Simultaneously Boiling and Condensing due to the Constant Heat Source and Heat Sink.

fluid. In order to simulate the system properly, the physical system must be numerically modeled equivalently and the lattice network must be of sufficient resolution with an appropriate time step [48]. These constraints assist in representing the correct physics for the system. While in many cases the physical system units are non-dimensionalized prior to discretizing the lattice, it is not absolutely necessary [48]. The model presented in this work maintained all units which allowed for better comparison with parameter calculations and experimental data.

\section{Experimental Method}

\subsection{Fabrication}

Prior to the production of a working MHE, fabrication methods were determined. There are five broad fabrication classifications for processing micro-channels: photolithography, expansion, solidification, subtractive, and 
additive $[49,50,51]$. All five methods potentially include expensive equipment or clean-room laboratory conditions that are capable of producing highquality micro-channel devices. There are, however, low-cost options which allow for ease of manufacture and a more widespread use of metal-based MHEs. A general laboratory method that did not require expansive cleanroom facilities was pursued for these devices for this reason. One important photolithography technique for metallic micro-structures is LIGA (German for lithography, galvanoformung (electroplating), and abformung (molding)) where thick photoresists are applied to substrates as molds and filled with electroplated metals [52]. An adaptation of LIGA involved using polyimide as the applied mold which is a low-cost alternative to traditional LIGA photoresists [53]. As an alternative to the polyimide, some researchers have used dry film photoresists as the mold due to numerous advantages [54, 55]. This adapted technique produces an efficient, high-precision, low-cost method when combined with a COTS mask process.

The fabrication of MHEs from the modified LIGA technique concentrated on electroplating copper onto copper substrates. To create the device shown in Figure 1, a 100-200 $\mu$ m layer of copper was electrodeposited onto the copper substrate to produce the reservoirs and micro-channels. This basic design was consistent with prior exchangers fabricated by our lab using nickel as the deposited material and a similar fabrication process to the one described here [5]. Overall dimensions of the exchangers were $22 \mathrm{~mm}$ in width and $44 \mathrm{~mm}$ in length. After the MHE bottom plate with channels was fabricated, 
another copper plate was polished for smoothness and used as the MHE lid. Since the system was designed for closed system operation, an access port was installed on the lid to allow addition of working fluid. The specific fabrication steps are discussed in the following paragraphs.

A rigid substrate was necessary to limit plating delamination and plating cracking due to device handling and operation. Copper 110 sheeting of $0.6 \mathrm{~mm}$ thickness was purchased (McMaster-Carr ${ }^{\circledR}$ ) for the substrate and lid construction. In order to create a process which minimized equipment and fabrication time, dry film (Elga Europe ${ }^{\circledR}$ Ordyl ${ }^{\circledR}$ ) was purchased for the MHE mask patterning. Electroplating and polishing was performed with solutions of copper sulfate/sulfuric acid and phosphoric acid (Alfa Aesar ${ }^{\circledR}$ ).

The copper substrate was initially cleaned with acetic acid solution to remove any residual contamination and rinsed with DI water. A flat iron was then heated on a hot plate to approximately $80^{\circ} \mathrm{C}$ in order to laminate the dry film onto the substrate. Once the dry film adhered to the substrate, the $300 \mu \mathrm{m}$ width channel mask was secured to the dry film. In traditional micro-fabrication processes, a mask aligner is used to expose the film. In this work however, a mercury light source was used for exposure which fell within the recommended wavelength for the dry film. This enabled future ability to manufacture the MHE outside of laboratory environments and in lower cost processes. After an exposure time of 15 seconds, the undeveloped dry film was removed from the substrate using the recommended potassium carbonate solution. Figure 3 depicts a sample with a developed dry film and 


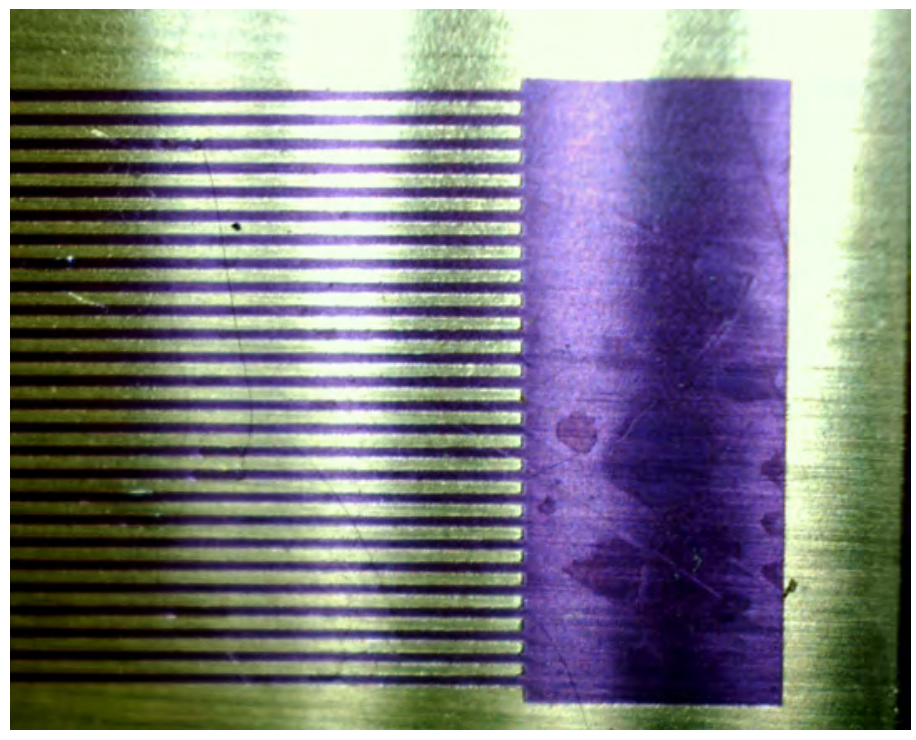

Figure 3: Copper Substrate with Developed Photoresist prior to Electroplating.

substrate prepared for electroplating.

Prior work indicated that electropolishing the copper substrate would provide an improved and cleaner surface for electroplating. Polishing the substrate creates a surface with enhanced uniformity, prevents delamination of plating, and allows for repeatability of fabricating MHEs. A phosphoric acid based solution was selected for the polishing step. Table 1 shows the final solution composition and conditions. The established mixture of copper sulfate and sulfuric acid was chosen for electroplating due to ease of preparation and accounting for chemical safety. Table 2 shows the final solution composition and conditions for electroplating.

The initial plating current density found in industry literature was $3 \frac{A}{d m^{2}}$ [57]. The plating area of the MHE, including outside boundary edges was 
Table 1: Copper Electropolishing Bath[56]

\begin{tabular}{c|c}
\hline $\mathrm{H}_{3} \mathrm{PO}_{4}$ & $157 \mathrm{~mL}$ \\
$\mathrm{H}_{2} \mathrm{O}$ & $75 \mathrm{~mL}$ \\
Current & $0.045 \mathrm{~A}$ \\
Temperature & $55^{\circ} \mathrm{C}$ \\
\hline
\end{tabular}

Table 2: Copper Electroplating Bath[57]

\begin{tabular}{c|c}
\hline $\mathrm{CuSO}_{4} 5 \mathrm{H}_{2} \mathrm{O}$ & $188 \frac{g}{L}$ \\
$\mathrm{H}_{2} \mathrm{SO}_{4}$ & $74 \frac{g}{L}$ \\
CurrentDensity & $3 \frac{\mathrm{A}}{d m^{2}}$ \\
Temperature & $37^{\circ} \mathrm{C}$ \\
\hline
\end{tabular}

$200 \mathrm{~mm}^{2}$. This corresponded to a current of 0.61A. Unfortunately, the sample plated uncontrollably in the narrow channel areas. In order to produce evenly plated equivalent channels, the current was lowered to $0.4 \mathrm{~A}$ which produced optimal channel geometries given economical plating time. Deposition rate of copper was also a required parameter for MHE repeatability. The aspect ratio of channel width to channel wall height has important effects on fluid flow through the MHE. As the aspect ratio approaches rises from 0 to 1 , the friction coefficient decreases, allowing fluid to minimize microscale surface effects [58]. Since the channel width was $300 \mu \mathrm{m}$, it was desired to have a channel height of at least $100 \mu \mathrm{m}$ giving a minimum aspect ratio of 0.3 . Given MHE geometry and a desired channel height of $100 \mu \mathrm{m}$, the minimum quantity of copper to electroplate was 0.003 moles. Several samples were plated for varying times, giving sample channel wall heights between $60 \mu \mathrm{m}$ and $200 \mu \mathrm{m}$, and a Dektak 150 Surface Profiler was used to measure the deposited channel wall heights. Using the fabrication method presented, the deposition rate of copper plating was determined to be approximately 


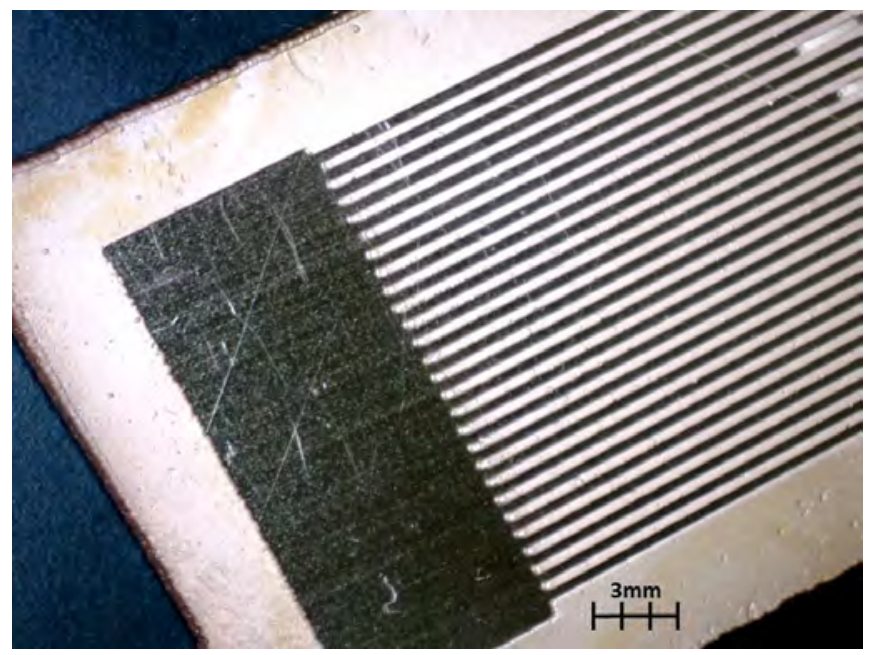

Figure 4: Copper MHE Base Substrate with Plated Micro-channels.

$1 \frac{\mu m}{m i n}$. Several examples of plated MHE channels of wall height $120 \mu \mathrm{m}$ were prepared, two of which are presented in Figures 4 and 5.

Once the MHE bottom was electroplated for 2 hours with a channel wall height of $120 \mu \mathrm{m}$, a second copper substrate was polished which served as the MHE lid. Before securing the lid to the plated substrate, an access port with diameter $3 \mathrm{~mm}$ was drilled into the center of the lid. Centering the access port provided equal dispersion of the working fluid, via the micro-channels, to the two reservoirs. The bottom plate and lid were then contacted with a press and bonded with epoxy on the vertical sides. The relative smoothness of the plating enhanced thermal contact between the plates; the external seal covered the entire vertical sides of both plates to ensure working fluid did not escape during operation due to the porosity of the electroplating process. The epoxy used for sealing the MHE side walls had a low thermal 


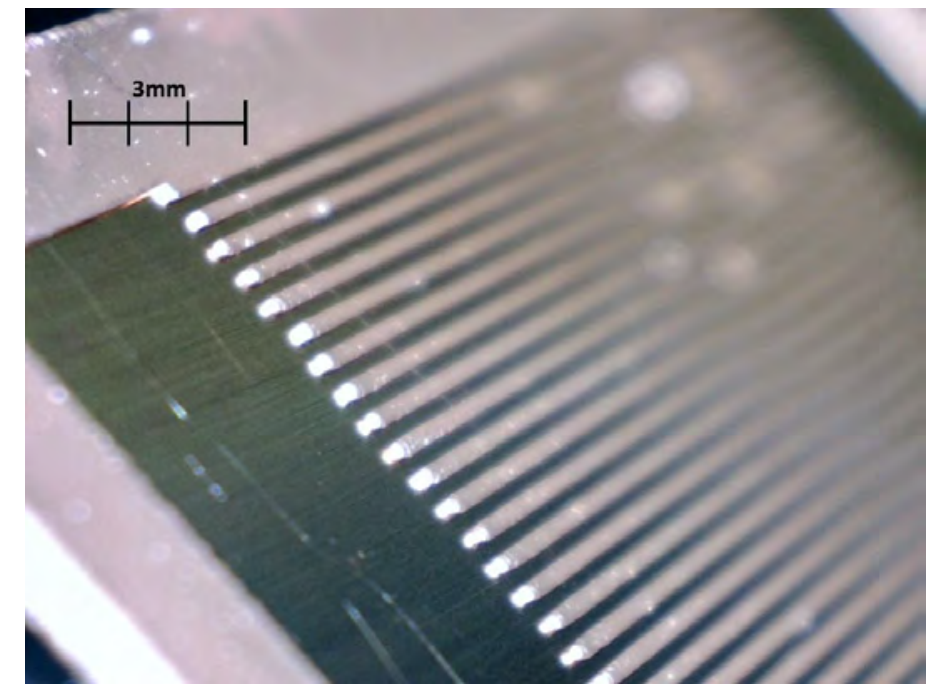

Figure 5: Copper Plated MHE Capillary Micro-channels.

conductivity which was beneficial for limiting side wall thermal losses. Facilitating device re-use in testing due to closed system operation, the MHE lid access port was sealed with Kapton tape and thermal paste after filling with working fluid. Figure 6 shows a completed MHE, ready for fluid fill and testing.

\subsection{Test Setup}

Prior to testing with working fluid, the MHEs were baselined in a dry condition. Devices were tested with no fluid first and then working fluid was added to the MHEs. The baseline measurement was performed to determine the energy lost to surroundings. The amount of fluid necessary to fill the MHE reservoirs and channels was $150 \mu \mathrm{L}$ based on the device geometry. This value was used to determine an appropriate volume of working fluid for test- 


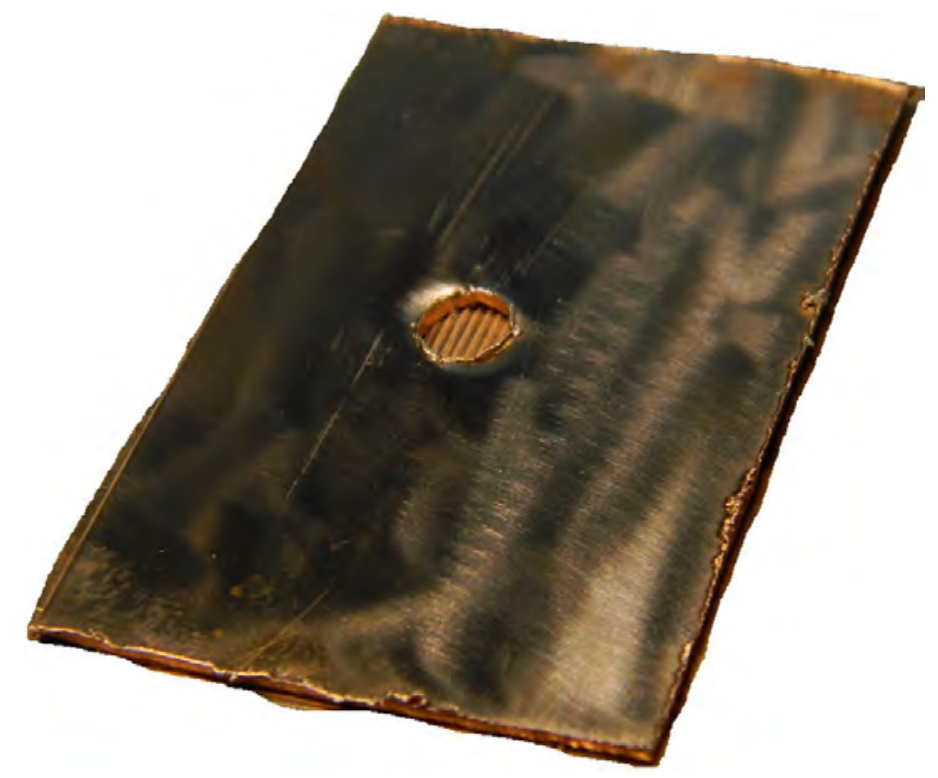

Figure 6: Completed MHE Sample with Lid and Access Port. Note the visibility of the channels through the Access Port.

ing. A vapor-liquid interface was desired so the MHE was not filled entirely with working fluid and forced into a pressurized pool boiling operating mode. In this operating mode, the capillary channels would be ineffective. Based on the necessity to have the vapor-liquid interface and condensation at the MHE lid, the volume of working fluid added to the MHE was $120 \mu \mathrm{L}$, or $80 \%$ of total MHE volume. The MHE was designed to have multiple applications in multiple environments. In this work, a low-temperature waste heat environment was targeted with temperatures below $150^{\circ} \mathrm{C}$. Therefore, $3 \mathrm{M}^{\circledR}$ HFE-7200 engineered fluid was selected as the working fluid. The low liquid viscosity increased capillary flow through the channels and the boiling point of $76^{\circ} \mathrm{C}$ was low enough to provide a testing platform for low-power input 
applications. Loading of the MHE fluid was performed by manually filling the MHE using a Gilson ${ }^{\circledR}$ Pipetman ${ }^{\mathrm{TM}}$ pipette. Following filling of the MHE, the devices were ready for testing.

Tests were conducted to characterize energy absorption and transfer of the MHE and temperature profiles of MHE bottom and lid. The fabricated MHEs were tested in a setup depicted in Figure 7. To minimize energy losses to surroundings, the testing was performed on a piece of balsa wood, which has a thermal conductivity twice that of air. Omega ${ }^{\circledR}$ k-type bare wire thermocouples (TC) were used to measure temperature at discrete points on the heater, heat sink, heat flux sensors, and the MHE. Omega ${ }^{\circledR}$ listed the error of each $\mathrm{TC}$ as $\pm 0.5^{\circ} \mathrm{C}$. The heat source of the test device was provided by an Omega ${ }^{\circledR}$ KHLV-101/10-P resistance heater. The heater was connected to a power supply with a measured $3.6 \mathrm{~W}$ input power maintained for every test. This power was selected to ensure the bottom of the MHE reached temperatures above the working fluid boiling point in order to cause the required and desired phase change.

To quantify the thermal energy transfer through the setup, an Omega ${ }^{\circledR}$ HFS-4 thin film heat flux sensor (HFS) was placed between each layer as noted in Figure 7. Worth noting was a method used to minimize energy loss through the test setup under Heater \#2. Heater \#1 and HFS \#1, from Figure 7, were included in order to offset heat output from Heater \#2 towards the setup base. The additional HFS underneath Heater \#2 was used to minimize energy loss through the balsa base by tracking HFS \#1 from Figure 7 and 


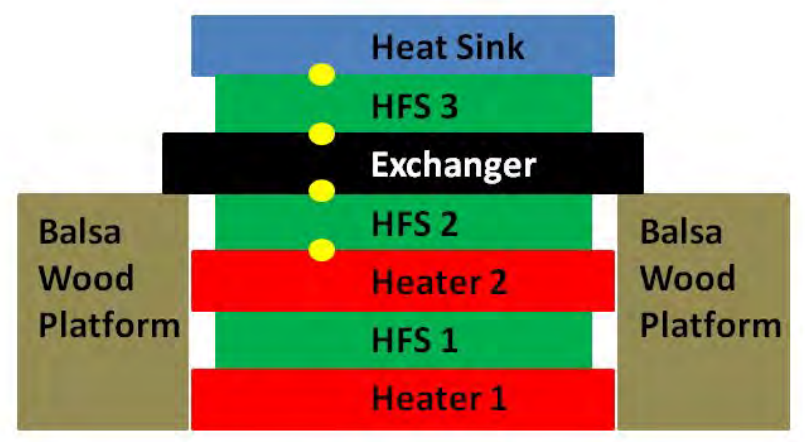

Figure 7: Test Setup with Thermocouples Shown as Yellow Circles.

maintaining a heat flux measurement of zero, such that Heater \#1 acted as a guard heater. This ensured that the majority of output from Heater \#2 was directed towards the MHE. The nominal sensitivity of each HFS-4 has an error of $\pm 10 \%$, according to Omega ${ }^{\circledR}$.

The heat sink used in the test setup was a Xigmatek A10 S80DP, typically used for cooling PC processors. The heat sink had enough thermal mass to hold constant temperature during device testing. A lab jack was used to ensure good thermal contact between the MHE, all sensors and heaters, and the heat sink. As shown in Figure 7, this setup was maintained for all tests. Care was taken to maximize thermal contact between setup layers by using Omega ${ }^{\circledR}$ Omegatherm ${ }^{\circledR} 201$ thermal paste. Data was recorded and analyzed via a Lab-View program on a connected PC. The two heat flux sensors (HFS \#2 and HFS \#3) provided heat flux data which was used to calculate energy transference and losses. Each HFS was calibrated and verified by Omega ${ }^{\circledR}$. The heat flux transfer through the MHE and temperature data allowed char- 
acterization of the MHE as described in the Experimental Results section.

\subsection{Experimental Results}

The results of prototype testing are included in this section. Tests were conducted to characterize the operation of the dry copper-based MHE versus a working fluid wetted MHE. The thermal testing reported how added thermal energy to the device altered heat flux and temperature measurements in order to characterize heat transfer and energy transference of the device. This was utilized in subsequent model evaluation and validation work.

Though the given energy input to the heater was $3.6 \mathrm{~W}$, resistive losses reduced energy input supplied to the MHE to $3.44 \mathrm{~W}$. This corresponded to a heat flux entering the MHE of $8.7 \frac{\mathrm{kW}}{\mathrm{m}^{2}}$. For the dry MHE, the output heat flux, measured at the interface between top MHE surface and heat sink, was $7.6 \frac{\mathrm{kW}}{\mathrm{m}^{2}}$ while the wetted MHE output was $8.3 \frac{\mathrm{kW}}{\mathrm{m}^{2}}$, depicted in Figure 8. The percentage of input flux which exited through the MHE was $87.5 \%$ for the dry MHE and $95.4 \%$ for the wetted MHE. Through the use of the working fluid, energy transfer through the device was increased by approximately $8 \%$. Energy rejected from the sides of the MHE was assumed negligible versus the overall thermal energy passing from source to sink. This was based on the operating temperatures, heat flux, and side cooling that was restricted to radiation or free convection. Direct calculation of the side losses for both the dry and wetted MHE tests yielded less than $1 \%$ of the total input power to the device. Remaining input which was lost to the surrounding environment 


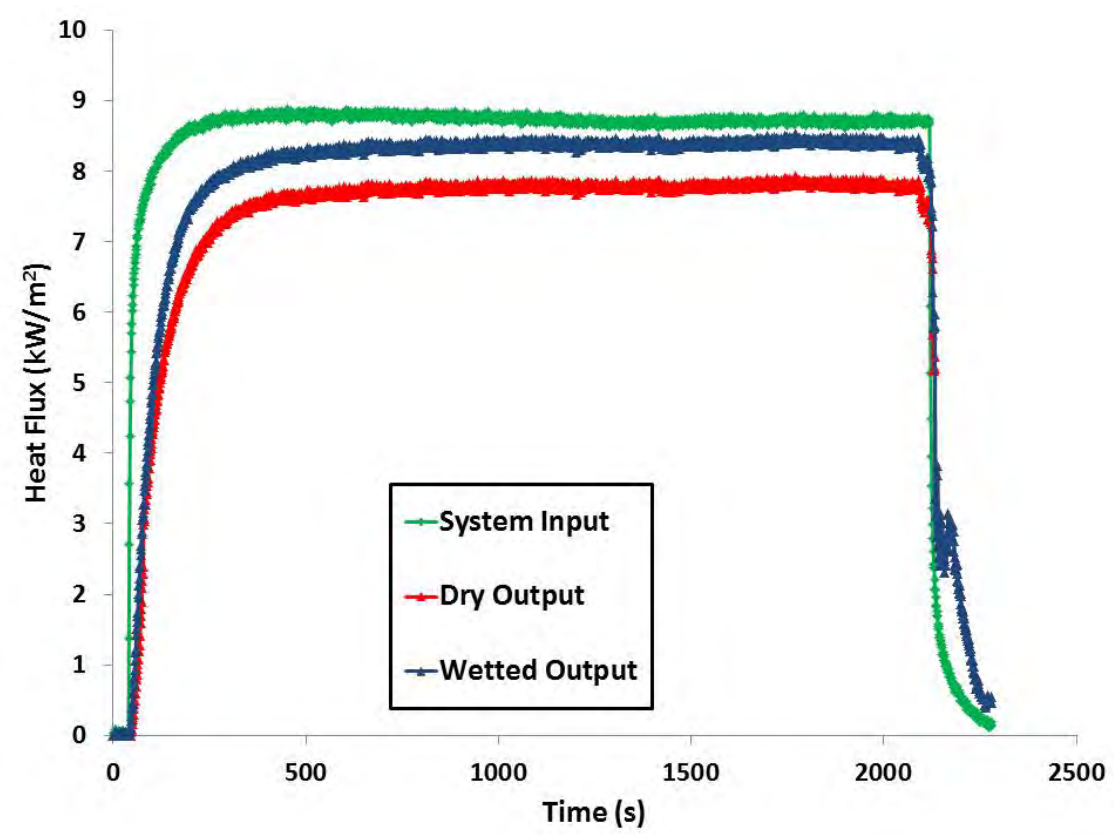

Figure 8: Heat Flux Data from Dry and Wetted Tests.

was the result of energy absorbed by the copper MHE due to the increase in experimental temperature, energy lost through the MHE bottom plate into the balsa wood base, energy absorbed by the working fluid and vapor due to increases in temperature, and the energy absorbed by the working fluid during phase change.

The temperature profile of the dry and wetted MHE also yielded interesting results. The working fluid acted as a heat sink, which lowered the measured thermocouple temperatures an average of $9^{\circ} \mathrm{C}$ except for the actual heat sink and heat source. Both the dry and wetted MHE testing yielded a heat sink temperature of $37^{\circ} \mathrm{C}$ while the heat source maintained a temper- 


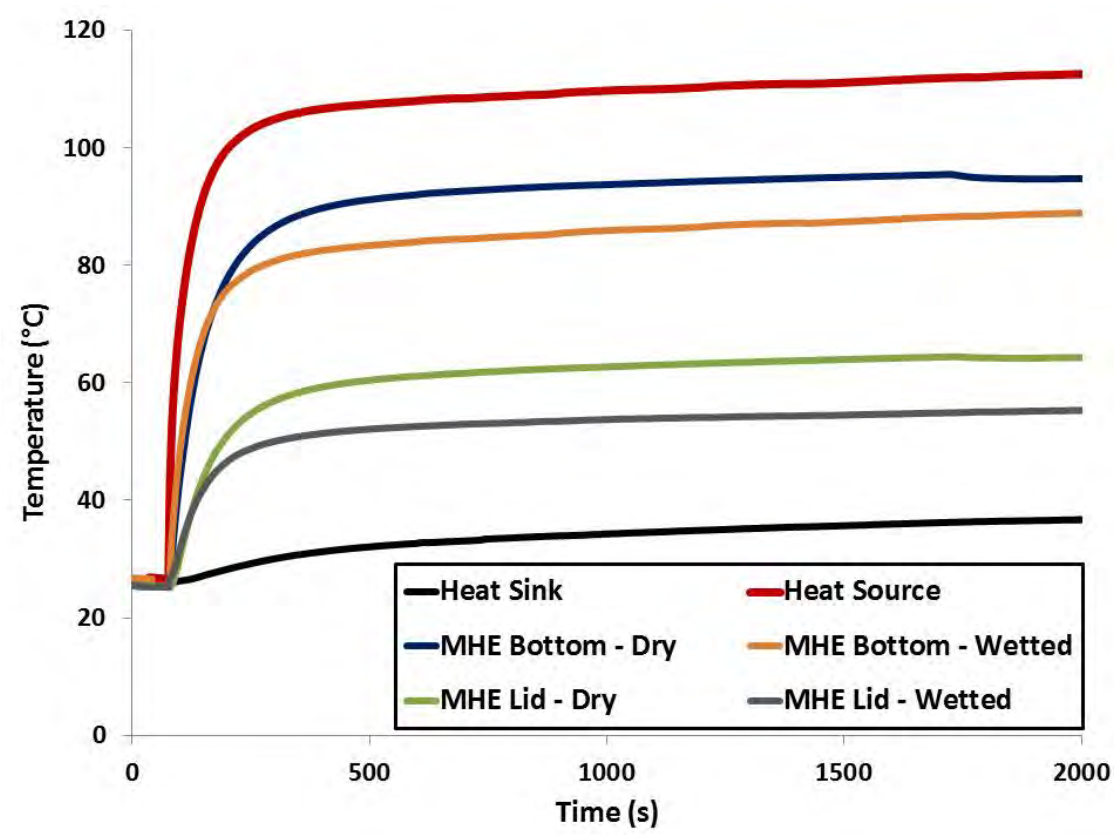

Figure 9: Dry MHE Temperature Data.

ature of $109^{\circ} \mathrm{C}$. The temperature data for the dry and wetted MHE tests are shown in Figure 9.

The underlying key to these tests was the contribution to efficiency through the use of the working fluid within the MHE. In the dry tests, there was only air in addition to the copper channels between the top and bottom which reduced the thermal conductivity and the energy transference of the MHE. However, after adding working fluid, the pocket was filled $80 \%$ with working fluid. The vapor-liquid interface allowed greater conductivity but also introduced phase change. The phase change within the channels was specifically examined in the complimentary modeling effort. The capillary action 
of the micro-channels pulled liquid over the heat source. Vaporization of fluid caused micro-channels to pull additional liquid and the temperature of the MHE lid indicated condensation of working fluid back to the channels and reservoirs to begin the cycle anew as shown in Figure 2. Subsequent modeling work examined this behavior in greater detail.

The channels themselves represented unique structures unlike standard micro-fabricated structures. SEM images of the plated copper are shown in Figures 10 and 11. Estimation of porosity was performed both with a linear bulk volume measurement and via the SEM software. Given the volume of the designed MHE, the fabricated sample was massed and converted to volume using the density of copper. It was calculated that the samples' average volume was $85 \%$ of the theoretical volume of the MHE, thus giving a porosity of $15 \%$. This agreed well with the SEM software which averaged porosity calculations to $16 \%$. The porous structure of the channels increased device surface area and enhanced contact area for the working fluid. Capillary and wicking action allowed working fluid to inundate the entire channel system, not just the capillary micro-channels. Liquid distribution in the MHE is primarily driven through the bi-directionality capillary flow in the main channels; however, because the channel walls are porous, there is also liquid distribution throughout the walls that act as a sponge. This behavior was previously noted using nickel-based porous channels [5]. Though the system is closed, this structure promoted a highly interactive vapor-liquid interface which increased overall heat transfer of the device. 


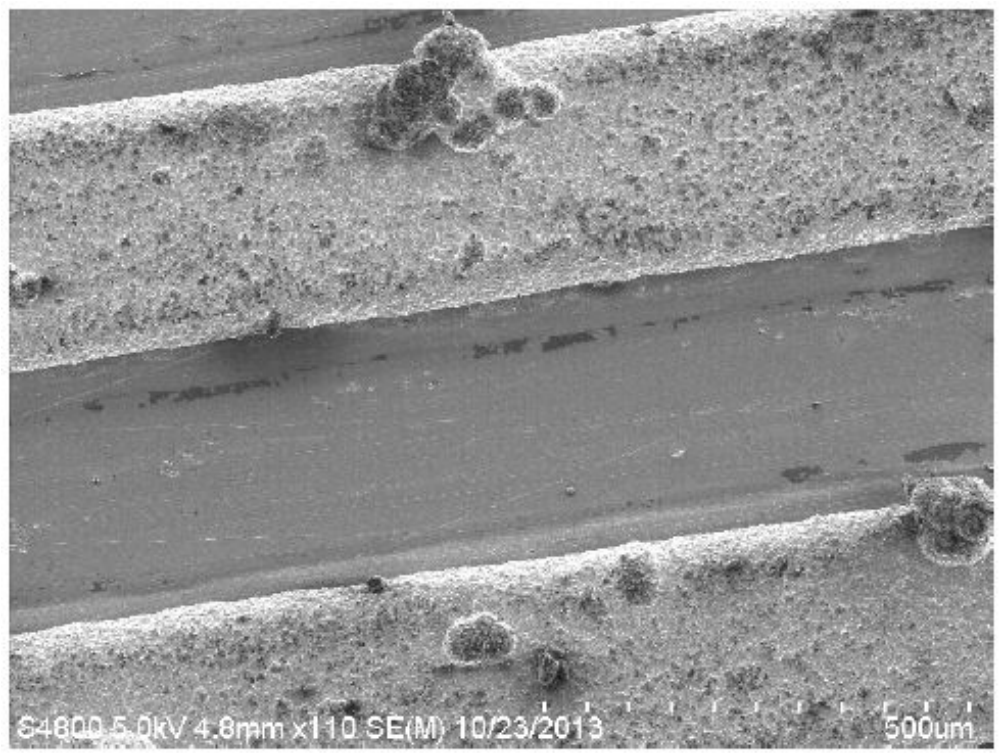

Figure 10: SEM Image of Plated Channels at $500 \mu \mathrm{m}$ Scale.

\section{Model Description}

Once the initial experimental boundary and initial conditions were tested and characterized, it was important to develop a model of the device interior to better characterize phase change activity and interior operation of the MHE. Due to symmetry, the simulation involved the momentum and energy transport along one channel length.

Prior to examining specific performance of the proposed model, a general description of the LBM model construction is given along with all fundamental equations. Since the MHE system includes multiple phases of working fluid, there is a need to establish both a density distribution function and a temperature distribution function in order to fully capture the particle evolu- 


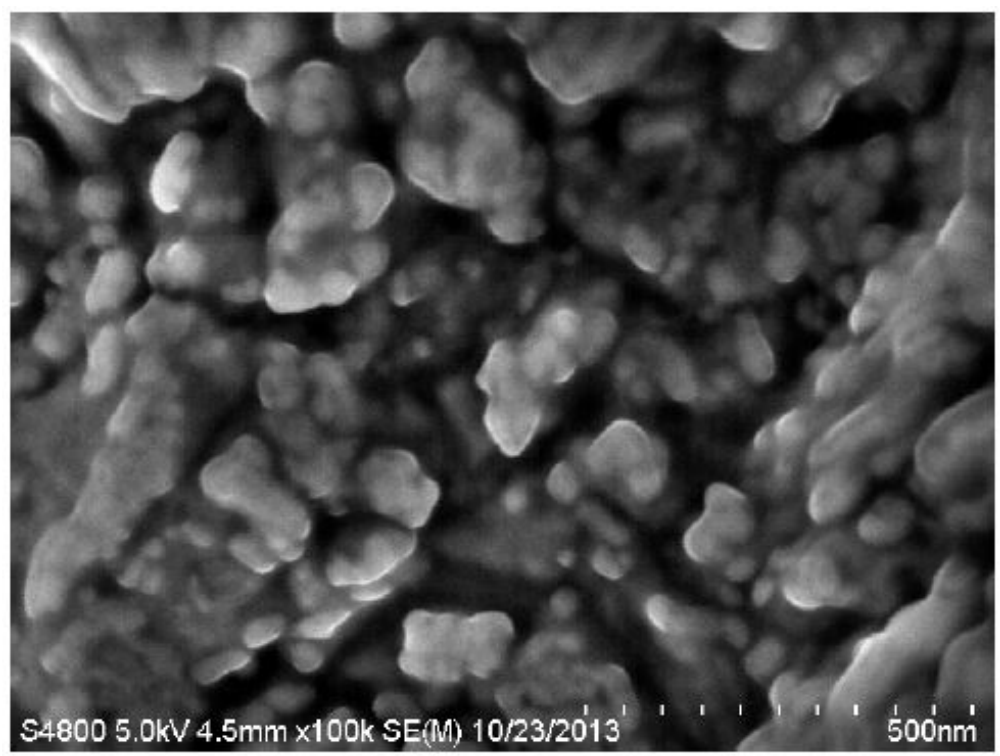

Figure 11: SEM Image of Plated Channels at 500nm Scale.

tion through lattice space and time. The LBM describes a single component or multi-component system by these evolutions of the particle distribution functions. The density distribution function evolves using the traditional BGK collision operator as given in Equation 1. A corresponding equilibrium distribution function relates the relaxation of the system, which is given in Equation 5. The last term in Equation 1 introduces a body force term as presented by Gong and Cheng [59]. This force term includes three forces which change associated velocity terms during collisions, the interparticle interaction force, the interaction force between surfaces and liquids, and the gravitational force [59]. 


$$
\begin{gathered}
f_{i}\left(\mathbf{x}+\mathbf{e}_{i} \delta_{t}, t+\delta_{t}\right)-f_{i}(\mathbf{x}, t)=-\frac{1}{\tau}\left(f_{i}(\mathbf{x}, t)-f_{i}^{e q}(\mathbf{x}, t)\right)+\Delta f_{i}(\mathbf{x}, t) \\
\Delta f_{i}(\mathbf{x}, t)=f_{i}^{e q}(\rho(\mathbf{x}, t), \mathbf{u}+\Delta \mathbf{u})-f_{i}^{e q}(\rho(\mathbf{x}, t), \mathbf{u})
\end{gathered}
$$

365 where

$$
\Delta \mathbf{u}=\mathbf{F} \cdot \delta t / \rho
$$

366 367 term, $\mathbf{F}$, is given by

$$
\begin{gathered}
\mathbf{F}=\mathbf{F}_{\text {int }}(\mathbf{x})+\mathbf{F}_{s}(\mathbf{x})+\mathbf{F}_{g}(\mathbf{x}) \\
f_{i}^{e q}=\omega_{i} \rho\left[1+\frac{\mathbf{e}_{i} \cdot \mathbf{u}}{c_{s}^{2}}+\frac{\left(\mathbf{e}_{i} \cdot \mathbf{u}\right)^{2}}{c_{s}^{2}}-\frac{u^{2}}{2 c_{s}^{2}}\right]
\end{gathered}
$$

368

369

370

Analogous to the density distribution functions evolution equation, the temperature distribution function has an evolution equation given by Equation 6. The equilibrium function, given by Equation 8, is very similar to the density equilibrium function. The main difference between the two distribution functions is the last term of each equation. While the density evolution 
incorporates a body force term, the temperature evolution uses an energy source term. Each distribution has with it an associated velocity, $e_{i}$, at position $\mathrm{x}$ and time $\mathrm{t}$. The weighting coefficients, $\omega_{i}$, for both equilibrium functions is based on statistical probability for particle movement.

$$
g_{i}\left(\mathbf{x}+\mathbf{e}_{i} \delta_{t}, t+\delta_{t}\right)-g_{i}(\mathbf{x}, t)=-\frac{1}{\tau_{T}}\left(g_{i}(\mathbf{x}, t)-g_{i}^{e q}(\mathbf{x}, t)\right)+\delta_{t} \omega_{i} \phi
$$

where

$$
\begin{gathered}
\phi=T\left[1-\frac{1}{\rho c_{v}}\left(\frac{\partial P}{\partial T}\right)_{\rho}\right] \nabla \cdot \mathbf{U} \\
g_{i}^{e q}=\omega_{i} T\left[1+\frac{\mathbf{e}_{i} \cdot \mathbf{U}}{c_{s}^{2}}+\frac{\left(\mathbf{e}_{i} \cdot \mathbf{U}\right)^{2}}{c_{s}^{2}}-\frac{U^{2}}{2 c_{s}^{2}}\right]
\end{gathered}
$$

There are many different LBM schemes based on system dimensionality and potential locations for the particles to move. For the proposed model the D2Q9 lattice scheme was selected due to system symmetry. The D2Q9 scheme is shorthand for two dimensional, nine discrete velocities within the momentum discretization [60]. Figure 12 depicts the velocities for the D2Q9 scheme. There are nine potential velocities and each has an associated probability, given in Equation 9. 


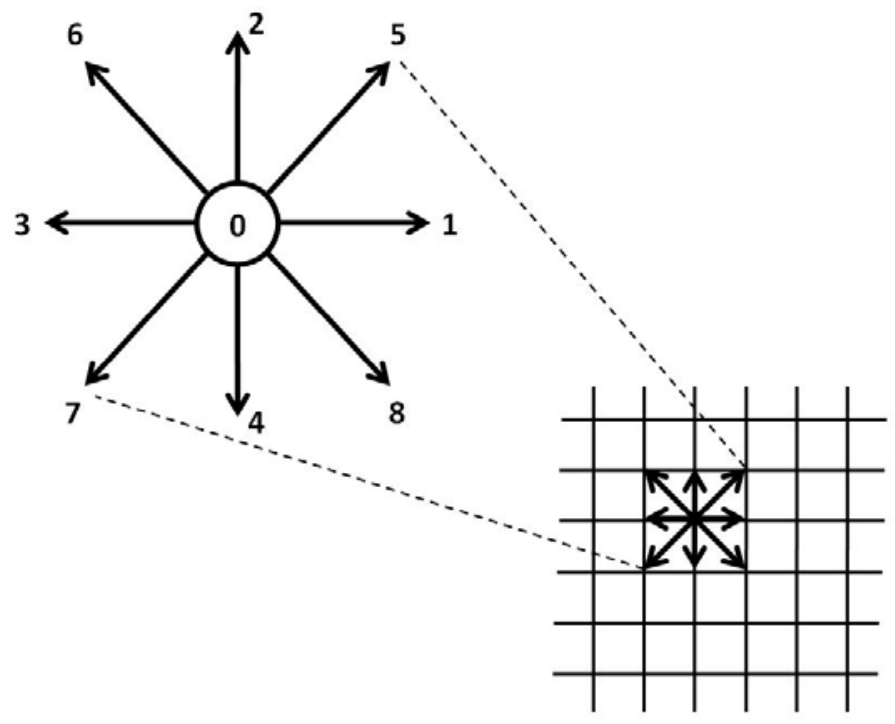

Figure 12: Particle Progression for D2Q9 LBM Scheme.

$$
\omega_{i}= \begin{cases}\frac{4}{9}, & i=0 \\ \frac{1}{9}, & i=1,2,3,4 \\ \frac{1}{36}, & i=5,6,7,8\end{cases}
$$

Before initializing the model with the density and temperature distribution functions, information given by $3 \mathrm{M}^{\circledR}$ was acquired concerning the working fluid in question, HFE-7200. The large amount of $3 \mathrm{M}^{\circledR}$ published data allowed for the use of two equations which correlate the density, temperature, and partial pressure of HFE-7200 [61]. This information was used to transform temperature data for boundary conditions into density data. 
401

$$
\ln P=22.289-3752.1(1 / T)
$$

$$
\rho=1.4811-0.0023026(T-273.15)
$$

Once the density distribution function was established and the temperature array was also calculated for the model, the pressure field needed to be determined. Since the pressure gives the phase change interface tracking, it was the overall objective of the simulation. In order to determine the pressure, an equation of state was used to associate all three variables of density, temperature, and pressure. The Peng-Robinson equation of state was chosen due to stability and accuracy for most models [59, 62]. Equation 12 gives the Peng-Robinson equation of state. The next section describes how the system was tested and the lattice parameters for model simulation.

$$
P=\frac{\rho R T}{1-b \rho}-\frac{a \rho^{2} \varepsilon(T)}{1+2 b \rho-b^{2} \rho^{2}}
$$

such that

$$
\varepsilon(T)=\left[1+\left(0.37464+1.54226 \omega-0.26992 \omega^{2}\right)\left(1-\sqrt{\frac{T}{T_{c}}}\right)\right]^{2},
$$


${ }_{412}$ with $\omega$ being the acentric factor. From correspondence with $3 \mathrm{M}^{\circledR}$ engineers, 413 the acentric factor was identified as 0.459 for HFE-7200.

414 3.0.1. Nomenclature

$\begin{array}{lll}\text { Symbol } & \text { Units } & \text { Description } \\ f_{i}(\mathbf{x}, t) & - & \text { Particle Distribution Function } \\ \tau & \mathrm{s} & \text { Relaxation Time } \\ \Delta f_{i}(\mathbf{x}, t) & \mathrm{N} & \text { Body Force Term } \\ \rho & \mathrm{g} / \mathrm{mL} & \text { Particle Density } \\ \mathbf{u} & \mathrm{m} / \mathrm{s} & \text { Particle Velocity } \\ \mathbf{F}_{\text {int }} & \mathrm{N} & \text { Interparticle Interaction Force } \\ \mathbf{F}_{s} & \mathrm{~N} & \text { Solid Surface/Fluid Interaction Force } \\ \mathbf{F}_{g} & \mathrm{~N} & \text { Gravitational Force } \\ f_{i}^{e q}(\mathbf{x}, t) & - & \text { Equilibrium Distribution Function } \\ \omega_{i} & - & \text { Weighting Coefficients } \\ \mathbf{e}_{i} & - & \text { Discrete Velocity Vector } \\ c_{s} & \mathrm{~m} / \mathrm{s} & \text { Lattice Sound Speed } \\ g_{i}(\mathbf{x}, t) & - & \text { Temperature Distribution Function } \\ \tau_{T} & \mathrm{~s} & \text { Temperature Relaxation Time } \\ \phi & - & \text { Energy Equation Source Term } \\ f_{i}^{e q}(\mathbf{x}, t) & - & \text { Equilibrium Distribution Function } \\ T & \mathrm{~K} & \text { Temperature } \\ \mathbf{U} & \mathrm{m} / \mathrm{s} & \text { Temperature Velocity }\end{array}$




$\begin{array}{lll}P & \text { bar } & \text { Pressure } \\ R & \frac{J}{\mathrm{Kmol}} & \text { Gas Constant } \\ b & \frac{\mathrm{m}^{3}}{\mathrm{~mol}} & \text { Peng-Robinson Constant } \\ a & \frac{\mathrm{kg} \cdot \mathrm{m}^{5}}{\mathrm{~s}^{2} \cdot \mathrm{mol}^{2}} & \text { Peng-Robinson Constant } \\ T_{c} & \mathrm{~K} & \text { Working Fluid Critical Temperature }\end{array}$

\subsection{Performance Setup}

The initial step in pursuing an LBM simulation is the selection of the program which will solve the model. Given the objectives of observing the density, temperature, and pressure fields and the arrays which will develop during the LBM, MATLAB ${ }^{T M}$ was selected. From the experimental data published previously, the first step for the program is to determine the boundary conditions of the system as well as the initial conditions for the fluid in channel. Symmetry of the channel and the bi-directionality of the fluid flow suggest periodic horizontal boundary conditions. The fixed top and bottom plating provides for the traditional LBM bounce back condition. While these boundary conditions apply to the momentum equations, there are also two additional boundary conditions which account for the heat sink and source. Therefore, temperature boundary conditions must also be set. This presents difficulty in programming where an additional temperature distribution function must be defined. However, one benefit of using a manufactured working fluid is the OEM data sheets and information which potentially provide alternative avenues to establishing a second distribution function. The boundary 


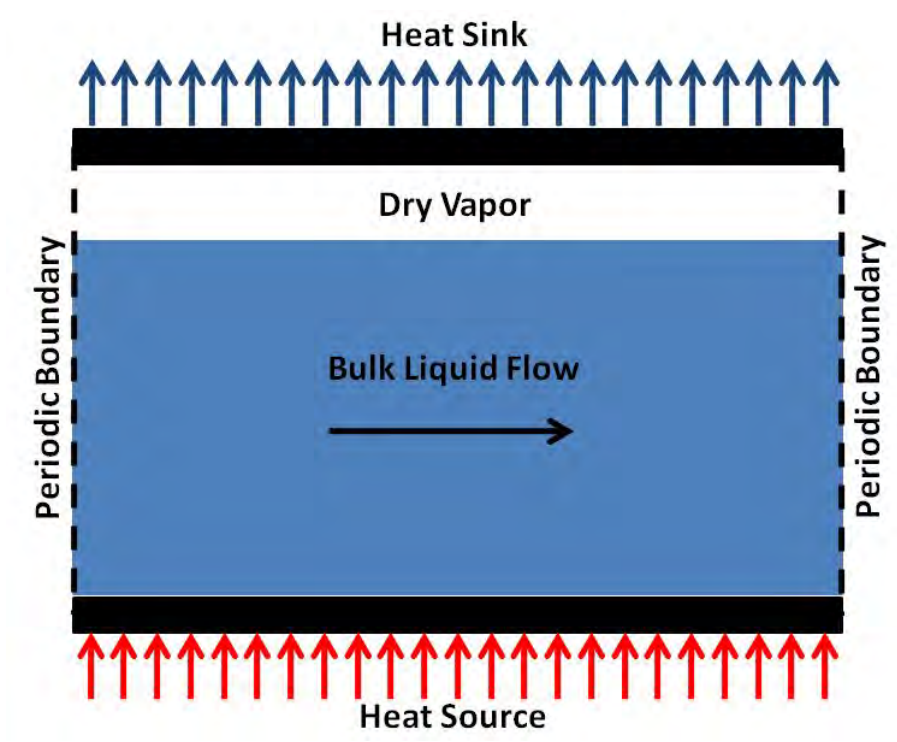

Figure 13: Boundary and Initial Conditions prior to Saturation.

conditions and initial conditions for the channel model are given in Figure 13.

The physical micro-channel had dimensions of $20 \mathrm{~mm}$ long, $300 \mu \mathrm{m}$ wide, and $120 \mu \mathrm{m}$ in height. Therefore, the ratio of length to height is approximately 166. While this ratio would simulate conditions along the entire channel, symmetry and bi-directionality of fluid motion due to capillary action allowed the physical ratio of the program to run at half of the channel size. Thus, the ratio used in the program is approximately 80 . The height of the simulation was halved such that LY was set to $60 \mu \mathrm{m}$ for scaling and reducing the computational power needed to perform the simulation, effectively producing a model having $2 \mu \mathrm{m}$ of actual dimension per $\mu \mathrm{m}$ of the simulation dimension. Therefore, the horizontal lattice was set to $4800 \mu \mathrm{m}$ to give the proper 
dimensionality of the simulated channel. However once again, due to symmetry and bi-directionality, the horizontal lattice was reduced to efficiently conduct the simulation without incurring too much computational power and memory. Temperature from the experimental testing fixed the bottom plate temperature at $85^{\circ} \mathrm{C}$ and the top plate temperature at $50^{\circ} \mathrm{C}$ for tests with working fluid. Time steps were tried to measure the steps necessary to ensure steady-state conditions. Following application of boundary and initial conditions along with channel dimensions for the simulation, working fluid properties were considered to provide the LBM-generated pressure field.

Product information for $3 \mathrm{M}^{\circledR}{ }^{\circledR}$ Novec $^{\mathrm{TM}}$ HFE-7200 fluid included Equations 10 and 11 which provided correlation between vapor pressure, density, and temperature [61]. Given these equations, the temperature boundary conditions were transformed into part of the density array for the lid and bottom boundary conditions. With the boundaries established for the density array, the channel initial conditions were fixed. Since $80 \%$ of the channel is filled with working fluid and $20 \%$ is air at room temperature, the inner array has initial densities of $1.43 \frac{\mathrm{g}}{\mathrm{mL}}$ for the working fluid and $0.0012 \frac{\mathrm{g}}{\mathrm{mL}}$ for dry air. Immediately after inserting working fluid into the MHE, the working fluid began evaporating until the dry air was saturated.

In order to fully understand the system equilibrium initial conditions with saturated vapor and bulk working fluid, Raoult's Law for a single condensable species was used which is given by Equation 14 . 


$$
p_{i}=y_{i} P=p_{i}(T)
$$

469

Therefore, for the HFE-7200/air system at ambient conditions, the molar composition calculation used the $3 \mathrm{M}^{\circledR}$ partial pressure equation.

$$
\ln P=22.289-\frac{3752.1}{298}=9.6981 \Longrightarrow P=0.163
$$

Therefore,

$$
y_{7200}=\frac{0.163}{1.01325}=0.1607 \frac{\text { mol7200 }}{\text { molmixture }}
$$

$$
y_{\text {air }}=1-y_{7200}=0.8393 \frac{\text { molair }}{\text { molmixture }}
$$

Using density properties and channel geometry measurements, the calculation of the initial density condition gave the saturated vapor density as less than the bulk working fluid density, at ambient temperature, by approximately $0.002 \%$. Thus, upon saturating the dry air of the channel, the system was assumed to have relatively uniform initial density. The dry air/working fluid interface tracked downward to provide the initial conditions of the simulation, shown in Figure 14.

In the two-dimensional system, the horizontal velocity component can be found by measurement of the physical device. Testing provided a flow velocity along the channel length of $20 \frac{\mathrm{mm}}{\mathrm{s}}$. At ambient temperature, $3 \mathrm{M}^{\circledR}$ published viscosity allows calculation of the Reynolds number to initially 


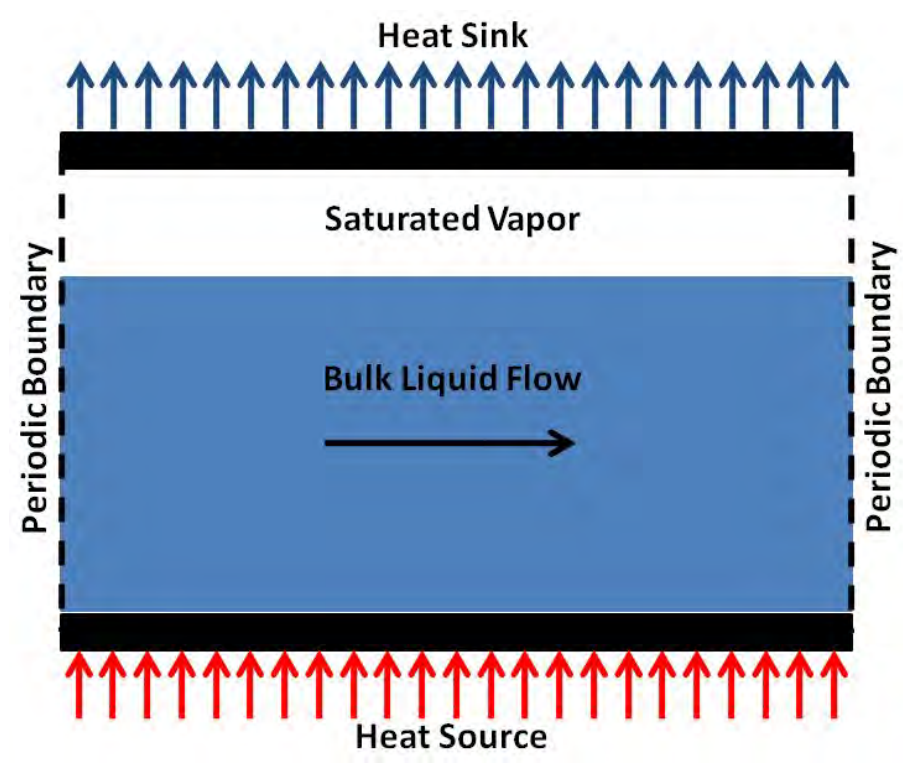

Figure 14: Boundary and Initial Conditions after Saturation.

be 975.6, giving laminar micro-channel fluid flow. Gravity and buoyancy effects were also accounted for in the flow profile. However, Cheng and $\mathrm{Wu}$ published a correlation shown in Equation 18 [63]. For the system in question, channel diameter was much less than the equation requires, revealing that gravity effects on the symmetry flow was negligible. Establishing the physical system, boundary and initial conditions, and fluid momentum within the model allowed solutions of LBM collisions. This was coupled with the two OEM equations and the equation of state to determine phase transitions within the channel.

$$
d_{c}=0.224 l_{c}
$$


Table 4: Peng-Robinson EOS parameters [61]

\begin{tabular}{c|c}
\hline$a$ & $3.6705 \frac{\mathrm{kgm}^{5}}{\mathrm{~s}^{2} \mathrm{~mol}^{2}}$ \\
$b$ & $0.00016 \frac{\mathrm{m}^{3}}{\mathrm{~mol}}$ \\
$R$ & $8.314 \frac{\mathrm{m}^{2} \mathrm{~Pa}}{\mathrm{Kmol}}$ \\
$T_{c}$ & $483.15 \mathrm{~K}$ \\
$P_{c}$ & $2.01 \mathrm{MPa}$ \\
\hline
\end{tabular}

In order to develop the pressure field, the parameters of the Peng-Robinson equation of state needed to be determined. Table 4 was generated from calculation and working fluid information from $3 \mathrm{M}^{\circledR}$. Note that all units were maintained due to the requirement that all model results be comparable to the experiment and experimental units. Taking all conditions and the physical system parameters into account, simulations were performed to solve for the phase change interface transitions. The results suggested promising simulations of the phase change regimes which occurred within the microchannel, reinforcing the fundamental MHE design and initial considerations of internal fluid flows.

\subsection{Simulation Results}

The initial simulations were plotted in intervals of 40 time steps for the density, temperature, and pressure arrays. The density array at the initial time step showed the dry air and bulk working fluid density difference. As time steps progressed, three interfaces began to form, one at the lid, one at the bulk vapor-liquid interface, and one at the bottom plate. The timebased progression of the central vapor-liquid interface moved $12 \mu \mathrm{m}$ from the lid down to approximately $23 \mu \mathrm{m}$ from the lid in the density array, shown in 


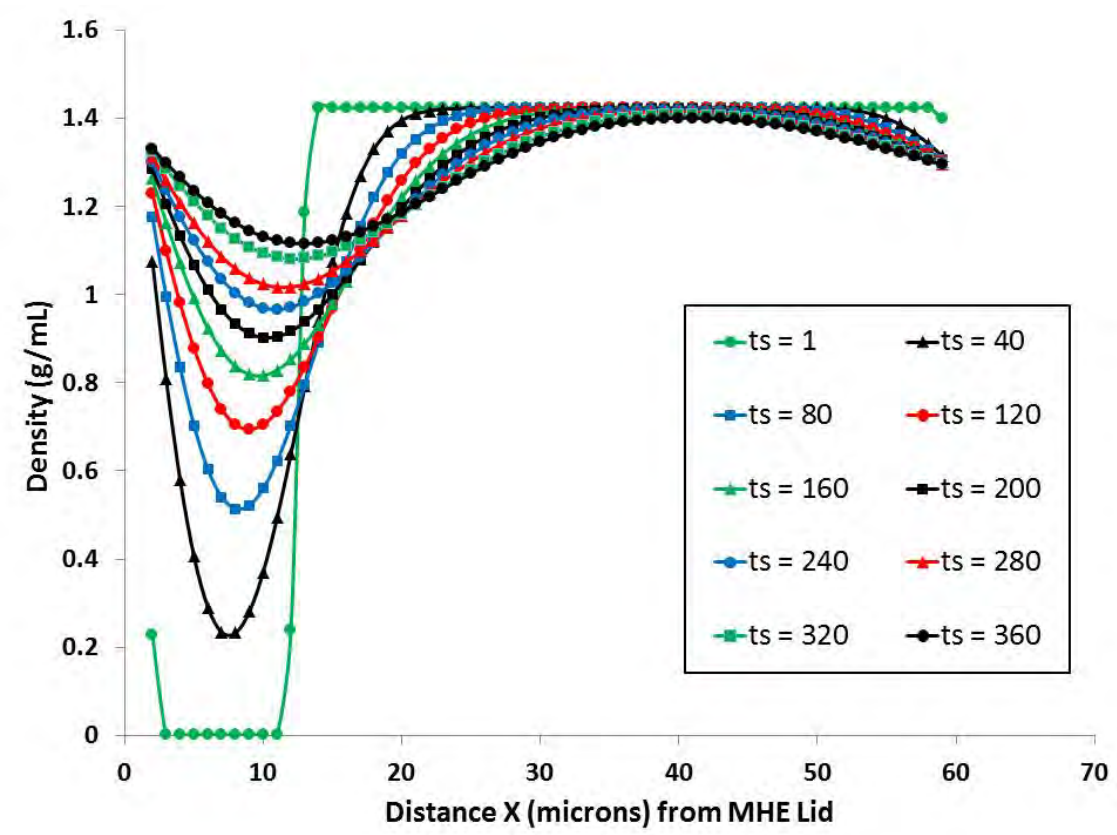

Figure 15: Time Progression for Density Array.

Figure 15. After 360 time steps, there was less than $1 \%$ change between the densities at time step 320 and step 360, suggesting that the density array had reached steady-state conditions. Time progression of the density as a function of position from the lid is given in Figure 15 while the percent change from each time step to the next is given in Figure 16.

The temperature array was simulated using Equation 11 and the density array. Another note for the temperature array was that at time step one, the air was already saturated with HFE-7200 using the calculation from Raoult's Law. The temperature as a function of position from the lid is plotted in Figure 17 which shows the temperature trends in the time progression mimic an 


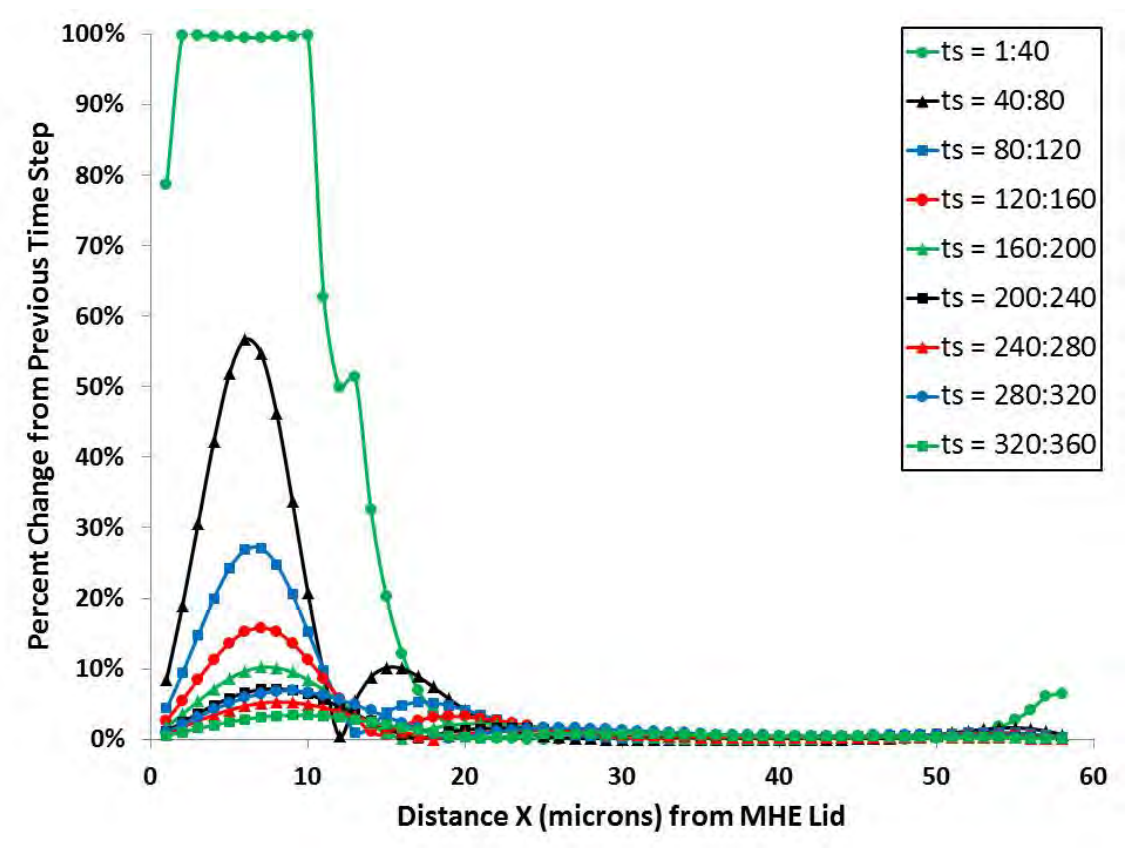

Figure 16: Percent Change in Density Array Time Progression.

inverse relationship to the density trends in Figure 15. Initially, the bulk fluid is at room temperature with the vapor showing a warming trend due to the heat sink kept at a constant temperature and the bulk liquid absorbing initial bottom plate heat source energy . The time progression shows bulk vapor increasing in temperature while the bulk liquid acts as an internal heat sink. While temperature increases at the lid, the density and temperature arrays indicate liquid conditions, indicating that condensation is occurring at the lid. The large increase in temperature at the bottom plate indicates boiling occurring, given density and temperature data. The pressure array is critical to the density and temperature arrays to confirm phase change. Similar to 


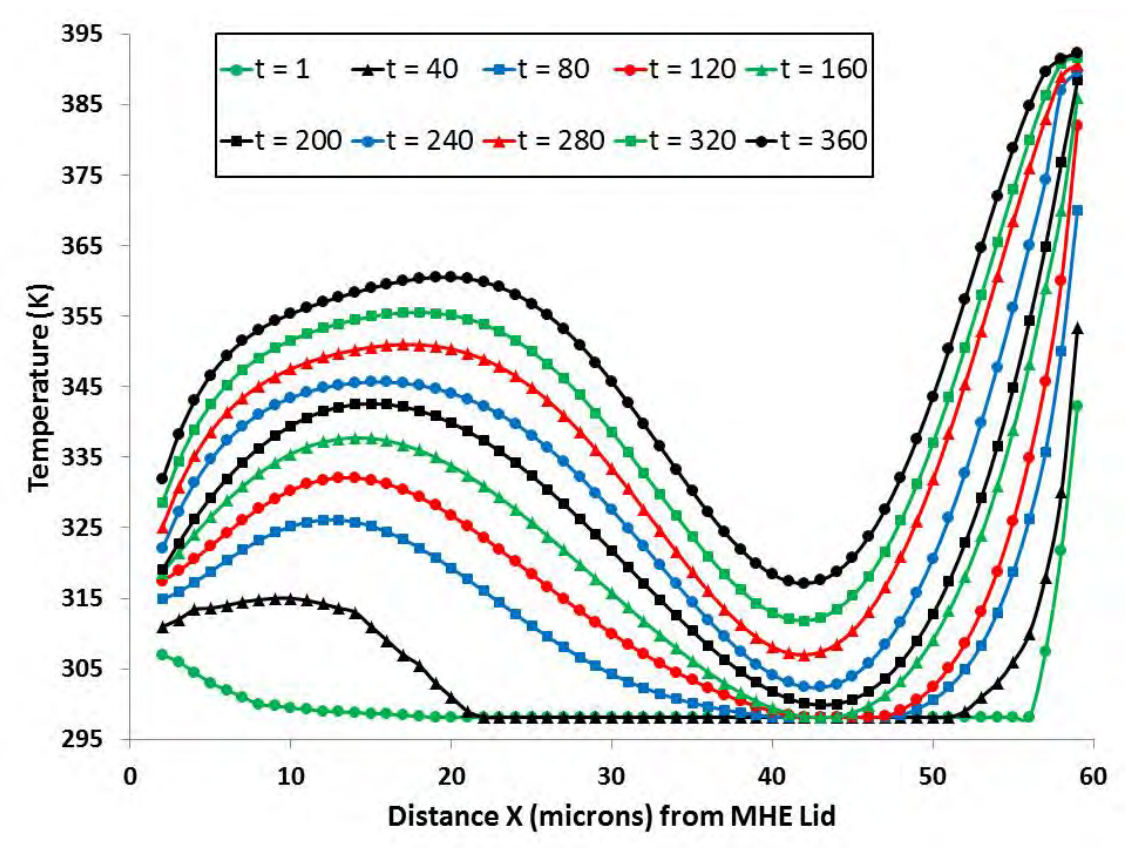

Figure 17: Time Progression for Temperature Array.

the density array, the largest changes were found in the span between time step 1 and time step 40, as shown in Figure 18. After 360 time steps, the temperature array percent change was less than $1 \%$, indicating steady-state conditions which agreed with the density array.

Both the density and temperature arrays were used to produce the pressure array from the Peng-Robinson equation of state, indicating where the phase change was occurring in the channel profile. Shown in Figure 19, the pressure array appears similar in pattern to the density array. The pressure array is the key to determining phase change within the micro-channel. Note in the plot that the low pressure in the $5 \mu \mathrm{m}$ to $20 \mu \mathrm{m}$ range indicates vapor 


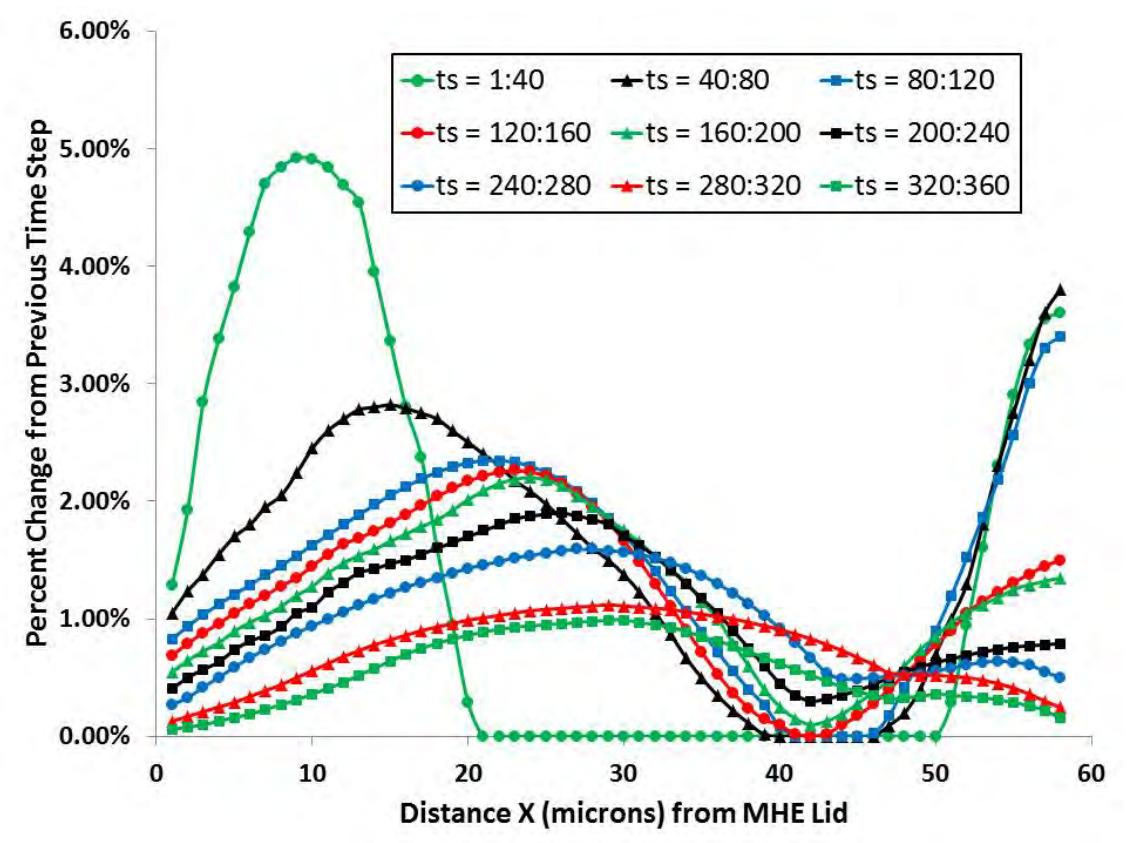

Figure 18: Percent Change in Temperature Array Time Progression.

phase in the channel. The bulk liquid phase is indicated by the leveling off of the pressure. Figure 20 reinforces Figures 16 and 18 suggesting the steadying of conditions after 360 time steps. Beyond the array plots, Figures 21 and 22 depict the time step progression of the pressure array with color maps in MATLAB ${ }^{T M}$. The phase interfaces at the MHE lid and bottom are small in comparison with the bulk vapor-liquid interface, shown in yellow. The white shade indicates conditions where there are vapor bubbles interacting with bulk liquid while the orange shade indicates conditions where liquid condensate is interacting with the bulk vapor.

The simulated cyclical operation of the MHE provides reinforcement that 


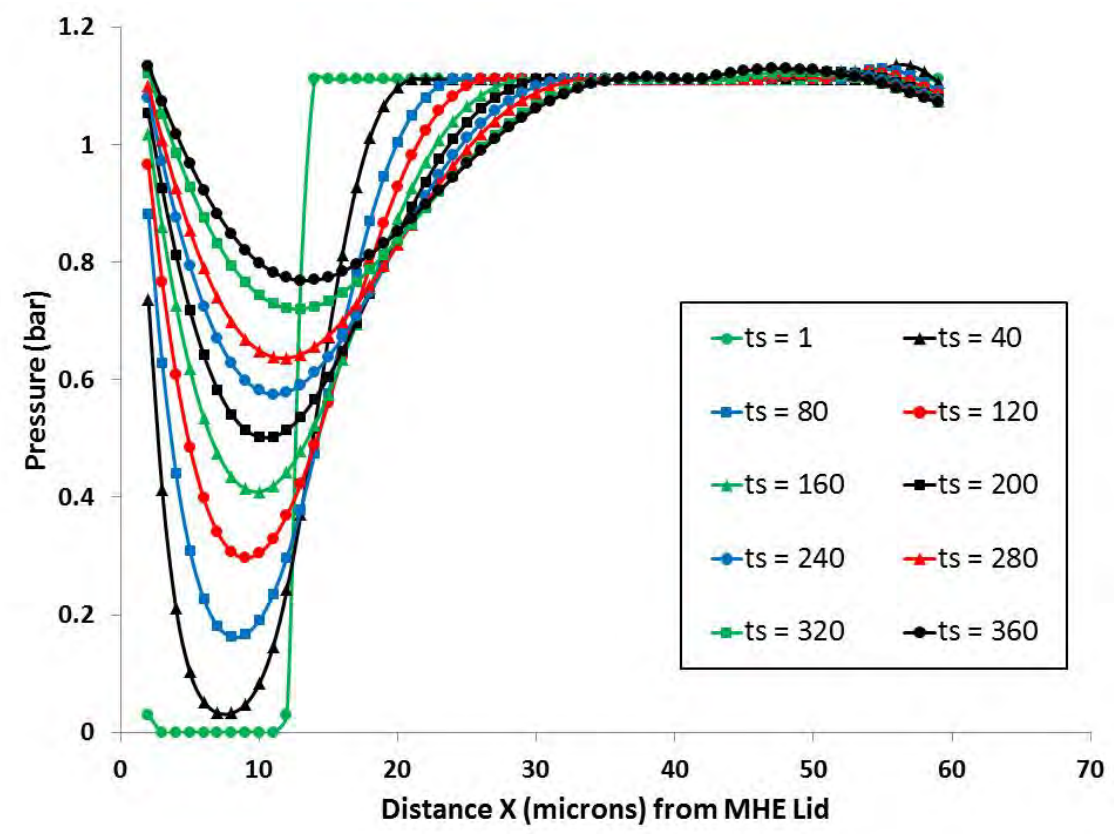

Figure 19: Time Progression for Pressure Array.

the experimental device is operating effectively as designed. Given the conditions of phase change at the heat source and heat sink, indicating boiling and condensation, and the large tracking vapor-liquid interface, the model reassures the operation of the experimental MHE as having a real internal fluid-vapor-fluid loop.

\section{Conclusion}

Fabrication and operation of a MHE has been investigated. The MHE acted in a closed system with operation based on development of capillary micro-channels which provided pump-like working fluid motion across a 


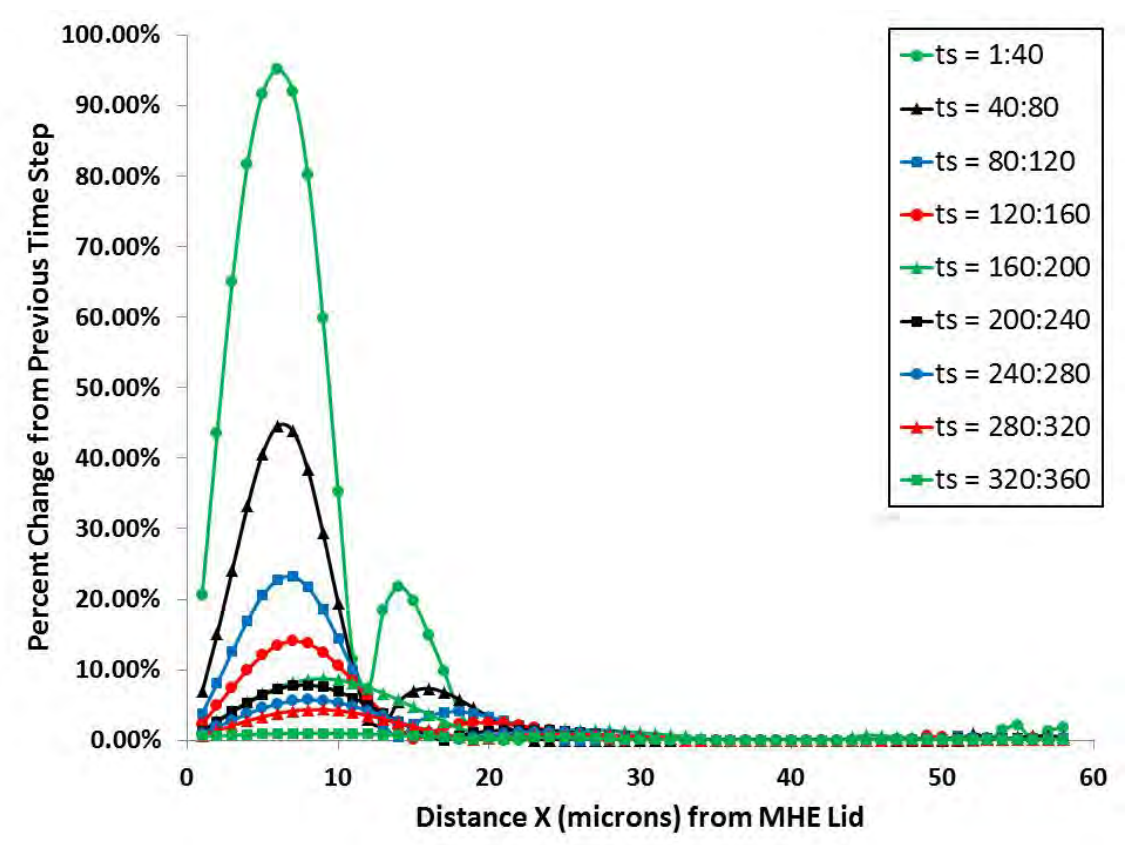

Figure 20: Percent Change in Pressure Array Time Progression.

heated surface, inducing phase change of the fluid. This operation provided a more efficient transfer of energy across the copper device when compared with dry operation.

Fabrication of the copper device was based on electroplating techniques that produced channel widths of $300 \mu \mathrm{m}$ with heights of $120 \mu \mathrm{m}$. The fabrication methodology proved that devices can be manufactured with minimal equipment and laboratory necessities. This added benefit was meant to potentially increase the global adoption and use of such devices.

The introduction of the working fluid improved the energy transfer of the device by approximately $8 \%$. With an energy flux supply of $8.7 \frac{\mathrm{kW}}{\mathrm{m}^{2}}$, a dry 


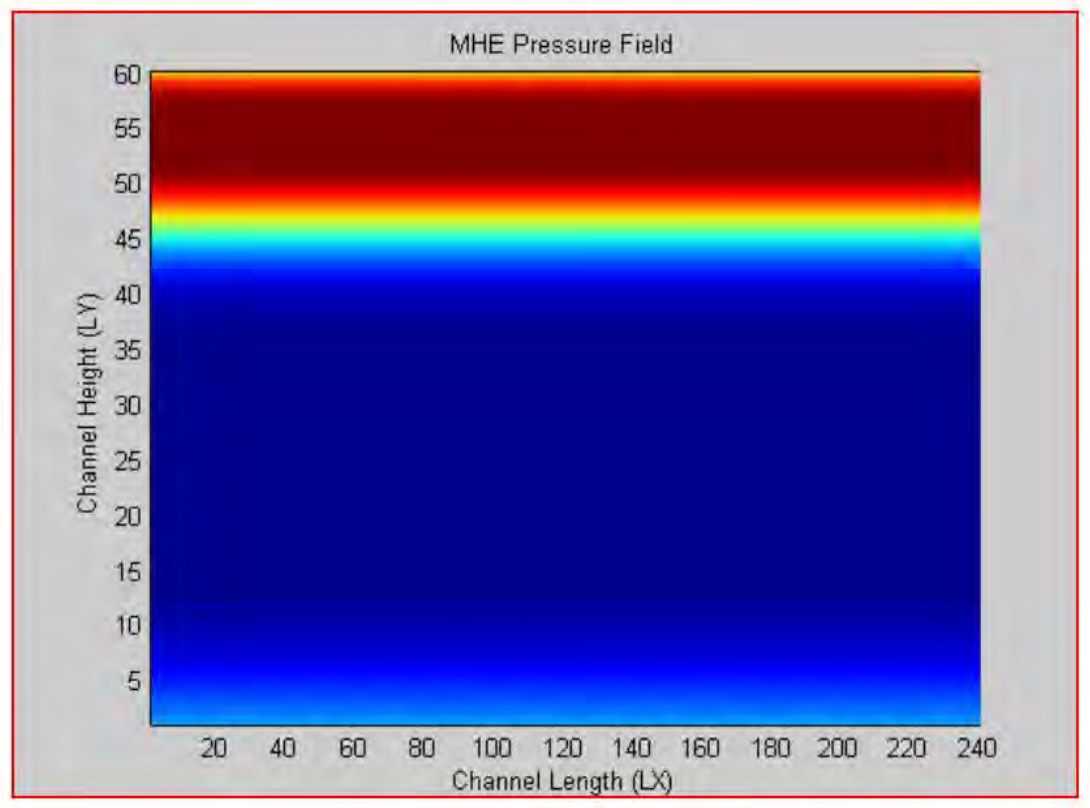

Figure 21: Color Map of Pressure at Initial Model Conditions

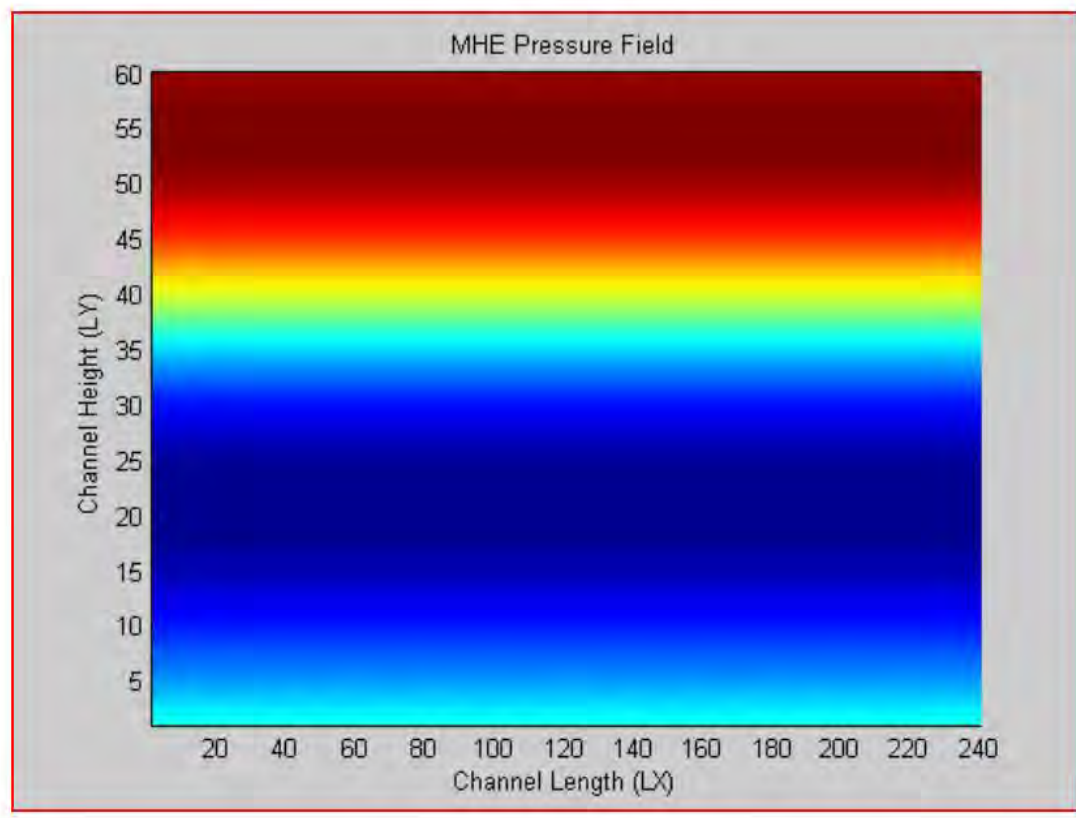

41

Figure 22: Color Map of Pressure at Steady-State Conditions $(\mathrm{ts}=360)$ 
device showed output flux of $7.6 \frac{\mathrm{kW}}{\mathrm{m}^{2}}$ whereas the wetted device showed output flux of $8.3 \frac{\mathrm{kW}}{\mathrm{m}^{2}}$. These results demonstrated the effectiveness of using working fluid and phase change within the devices. Use of working fluid, coupled with the development of copper techniques allowed a device to be fabricated entirely of copper. This increased thermal conductivity of the device when compared to traditional materials such as silicon and aluminum.

The closed system operation of the MHE required internal operation analysis via a simulated model using the lattice Boltzmann method. While a dual distribution function was needed for the multi-phase system, an alternative solution for programming was used whereby equations from the manufacturer, relating the temperature, density, and pressure, provided the necessary correlations to produce the system properties. The simulated micro-channel indicated that three areas of phase interface developed which reinforced the initial MHE design and cyclical operation of the working fluid.

The MHE presented was designed to be an efficient transfer device for waste energy which was fabricated using basic equipment and concepts. After testing the device both experimentally and using a simulated model, the MHE did provide a platform that accomplished its design objectives.

\section{Acknowledgement}

The authors gratefully acknowledge the support of this work by NASA via Contract NNX14CS11C and the NSF via Grant No. ECCS-1053729. 


\section{References}

[1] S. Thapa, E. Ogbonnaya, C. Champagne, L. Weiss, Mems-based boiler operation from low temperature heat transfer and thermal scavenging, Micromachines 3 (2) (2012) 331-344.

[2] J. W. Judy, Microelectromechanical systems (MEMS): fabrication, design and applications, Smart materials and Structures 10 (6) (2001) 1115.

[3] B. Mathew, B. Jakub-Wood, E. Ogbonnaya, L. Weiss, Investigation of a MEMS-based capillary heat exchanger for thermal harvesting, International Journal of Heat and Mass Transfer 58 (1) (2013) 492-502.

[4] Q. Gao, J. Lizarazo-Adarme, B. K. Paul, K. R. Haapala, An Economic and Environmental Assessment Model for Microchannel Device Manufacturing: Part 2-Application, Journal of Cleaner Production .

[5] E. Ogbonnaya, C. Champagne, L. Weiss, Simple and low cost method for metal-based micro-capillary channels for heat exchanger use, Journal of Micromechanics and Microengineering 23 (11) (2013) 115013.

[6] D. B. Tuckerman, R. Pease, High-performance heat sinking for VLSI, Electron Device Letters, IEEE 2 (5) (1981) 126-129.

[7] S. G. Kandlikar, History, advances, and challenges in liquid flow and flow boiling heat transfer in microchannels: a critical review, Journal of Heat Transfer 134 (3) (2012) 034001. 
[8] S. V. Garimella, C. Sobhan, Transport in microchannels-a critical review, Annual review of heat transfer 13 (13).

[9] W. Qu, I. Mudawar, Transport phenomena in two-phase micro-channel heat sinks, Journal of Electronic Packaging 126 (2) (2004) 213-224.

[10] L. Zhang, J.-M. Koo, L. Jiang, M. Asheghi, K. E. Goodson, J. G. Santiago, T. W. Kenny, Measurements and modeling of two-phase flow in microchannels with nearly constant heat flux boundary conditions, Microelectromechanical Systems, Journal of 11 (1) (2002) 12-19.

[11] I. Mudawar, Assessment of high-heat-flux thermal management schemes, Components and Packaging Technologies, IEEE Transactions on 24 (2) (2001) 122-141.

[12] L. Jiang, M. Wong, Y. Zohar, Forced convection boiling in a microchannel heat sink, Microelectromechanical Systems, Journal of 10 (1) (2001) 80-87.

[13] J. R. Thome, Boiling in microchannels: a review of experiment and theory, International Journal of Heat and Fluid Flow 25 (2) (2004) 128139.

[14] J. Lee, I. Mudawar, Two-phase flow in high-heat-flux micro-channel heat sink for refrigeration cooling applications: Part IIheat transfer characteristics, International Journal of Heat and Mass Transfer 48 (5) (2005) 941-955. 
[15] W. Qu, I. Mudawar, Flow boiling heat transfer in two-phase microchannel heat sinks--I. Experimental investigation and assessment of correlation methods, International Journal of Heat and Mass Transfer 46 (15) (2003) 2755-2771.

[16] T. J. Hendricks, Microchannel and Minichannel Heat Exchangers in Advanced Energy Recovery and Conversion Systems, in: ASME 2006 International Mechanical Engineering Congress and Exposition, American Society of Mechanical Engineers, 15-24, 2006.

[17] M. F. Remeli, L. Tan, A. Date, B. Singh, A. Akbarzadeh, Simultaneous power generation and heat recovery using a heat pipe assisted thermoelectric generator system, Energy Conversion and Management 91 (2015) 110-119.

[18] B. S. Yilbas, A. Z. Sahin, Thermal characteristics of combined thermoelectric generator and refrigeration cycle, Energy Conversion and Management 83 (2014) 42-47.

[19] M. Remeli, A. Date, B. Bhathal Singh, L. Tan, A. Akbarzadeh, et al., Power generation and heat recovery using heat pipe thermoelectric generator (HPTEG), in: SOLAR 2014, Australian Solar Council, 1-9, 2014.

[20] S.-C. Tzeng, T.-M. Jeng, Y.-L. Lin, Parametric study of heat-transfer design on the thermoelectric generator system, International Communications in Heat and Mass Transfer 52 (2014) 97-105. 
[21] W.-H. Chen, C.-C. Wang, C.-I. Hung, Geometric effect on cooling power and performance of an integrated thermoelectric generation-cooling system, Energy Conversion and Management 87 (2014) 566-575.

[22] X. Liu, Y. Deng, Z. Li, C. Su, Performance analysis of a waste heat recovery thermoelectric generation system for automotive application, Energy Conversion and Management 90 (2015) 121-127.

[23] J. Yang, Potential applications of thermoelectric waste heat recovery in the automotive industry, in: Thermoelectrics, 2005. ICT 2005. 24th International Conference on, IEEE, 170-174, 2005.

[24] J. R. Armstead, S. A. Miers, Review of waste heat recovery mechanisms for internal combustion engines, Journal of Thermal Science and Engineering Applications 6 (1) (2014) 014001.

[25] X. Liu, Y. Deng, K. Zhang, M. Xu, Y. Xu, C. Su, Experiments and simulations on heat exchangers in thermoelectric generator for automotive application, Applied Thermal Engineering 71 (1) (2014) 364-370.

[26] J. Pandit, Numerical and Experimental Design of High Performance Heat Exchanger System for A Thermoelectric Power Generator for Implementation in Automobile Exhaust Gas Waste Heat Recovery .

[27] Y. Zhang, M. Cleary, X. Wang, N. Kempf, L. Schoensee, J. Yang, G. Joshi, L. Meda, High-temperature and high-power-density nanos- 
tructured thermoelectric generator for automotive waste heat recovery, Energy Conversion and Management 105 (2015) 946-950.

[28] J. Song, C.-w. Gu, Parametric analysis of a dual loop Organic Rankine Cycle (ORC) system for engine waste heat recovery, Energy Conversion and Management 105 (2015) 995-1005.

[29] R. Daghigh, A. Shafieian, An investigation of heat recovery of submarine diesel engines for combined cooling, heating and power systems, Energy Conversion and Management 108 (2016) 50-59.

[30] F. Yang, X. Dong, H. Zhang, Z. Wang, K. Yang, J. Zhang, E. Wang, H. Liu, G. Zhao, Performance analysis of waste heat recovery with a dual loop organic Rankine cycle (ORC) system for diesel engine under various operating conditions, Energy Conversion and Management 80 (2014) 243-255.

[31] Ö. Kaşka, Energy and exergy analysis of an organic Rankine for power generation from waste heat recovery in steel industry, Energy Conversion and Management 77 (2014) 108-117.

[32] B. M. Fronk, K. R. Zada, Application of Microchannel Condensers for Small Scale Kalina Waste Heat Recovery Systems, in: ASME 2015 13th International Conference on Nanochannels, Microchannels, and Minichannels collocated with the ASME 2015 International Technical Conference and Exhibition on Packaging and Integration of Electronic 
and Photonic Microsystems, American Society of Mechanical Engineers, V001T03A007-V001T03A007, 2015.

[33] S. Thapa, E. Borquist, A. Baniya, L. Weiss, Experimental and computational investigation of a MEMS-based boiler for waste heat recovery, Energy Conversion and Management 100 (2015) 403-413.

[34] S. Quoilin, O. Dumont, K. H. Hansen, V. Lemort, Design, Modeling, and Performance Optimization of a Reversible Heat Pump/Organic Rankine Cycle System for Domestic Application, Journal of Engineering for Gas Turbines and Power 138 (1) (2016) 011701.

[35] Y. Feng, T. Hung, Y. Zhang, B. Li, J. Yang, Thermoeconomic comparison between pure and mixture working fluids of organic Rankine cycles (ORCs) for low temperature waste heat recovery, Energy Conversion and Management 106 (2015) 859-872.

[36] J.-C. Chang, T.-C. Hung, Y.-L. He, W. Zhang, Experimental study on low-temperature organic Rankine cycle utilizing scroll type expander, Applied Energy 155 (2015) 150-159.

[37] K. V. Selvan, M. S. M. Ali, Micro-scale energy harvesting devices: Review of methodological performances in the last decade, Renewable and Sustainable Energy Reviews 54 (2016) 1035-1047.

[38] B. Peris, J. Navarro-Esbrí, F. Molés, J. P. Martí, A. Mota-Babiloni, Experimental characterization of an Organic Rankine Cycle (ORC) for 
micro-scale CHP applications, Applied Thermal Engineering 79 (2015) $1-8$.

[39] D. Yang, M. Krasowska, C. Priest, M. N. Popescu, J. Ralston, Dynamics of capillary-driven flow in open microchannels, The Journal of Physical Chemistry C 115 (38) (2011) 18761-18769.

[40] D. Juncker, H. Schmid, U. Drechsler, H. Wolf, M. Wolf, B. Michel, N. de Rooij, E. Delamarche, Autonomous microfluidic capillary system, Analytical chemistry 74 (24) (2002) 6139-6144.

[41] N. Ichikawa, K. Hosokawa, R. Maeda, Interface motion of capillarydriven flow in rectangular microchannel, Journal of colloid and interface science 280 (1) (2004) 155-164.

[42] N. Ichikawa, R. Maeda, Interface motion driven by capillary action in circular and rectangular microchannel, Microscale Thermophysical Engineering 9 (3) (2005) 237-254.

[43] G. Fisher, M. R. Seacrist, R. W. Standley, Silicon crystal growth and wafer technologies, Proceedings of the IEEE 100 (Special Centennial Issue) (2012) 1454-1474.

[44] Y. Zhu, K. Petkovic-Duran, Capillary flow in microchannels, Microfluidics and Nanofluidics 8 (2) (2010) 275-282.

[45] S. Franssila, Introduction to microfabrication, John Wiley \& Sons Ltd, 2004. 
[46] F. Mei, P. R. Parida, J. Jiang, W. J. Meng, S. V. Ekkad, Fabrication, assembly, and testing of $\mathrm{Cu}$-and Al-based microchannel heat exchangers, Microelectromechanical Systems, Journal of 17 (4) (2008) 869-881.

[47] L.-S. Luo, Theory of the lattice Boltzmann method: Lattice Boltzmann models for nonideal gases, Physical Review E 62 (4) (2000) 4982.

[48] J. Latt, Choice of units in lattice Boltzmann simulations, Freely available online at http://lbmethod. org/_media/howtos: lbunits. pdf .

[49] K. P. Monroy-Vázquez, A. Attanasio, E. Ceretti, H. R. Siller, N. J. Hendrichs-Troeglen, C. Giardini, Evaluation of superficial and dimensional quality features in metallic micro-channels manufactured by micro-end-milling, Materials 6 (4) (2013) 1434-1451.

[50] D. C. Denkenberger, M. J. Brandemuehl, J. M. Pearce, J. Zhai, Expanded microchannel heat exchanger: design, fabrication, and preliminary experimental test, Proceedings of the Institution of Mechanical Engineers, Part A: Journal of Power and Energy (2012) 0957650912442781.

[51] T. A. Ameel, R. O. Warrington, R. S. Wegeng, M. K. Drost, Miniaturization technologies applied to energy systems, Energy Conversion and Management 38 (10) (1997) 969-982.

[52] R. C. Jaeger, Introduction to Microelectronic Fabrication: Volume 5 of Modular Series on Solid State Devices, Prentice Hall, 2001. 
[53] M. G. Allen, et al., High aspect ratio electroplated microstructures using a photosensitive polyimide process, in: Micro Electro Mechanical Systems, 1992, MEMS'92, Proceedings. An Investigation of Micro Structures, Sensors, Actuators, Machines and Robot. IEEE, IEEE, 87-92, 1992.

[54] H. Lorenz, L. Paratte, R. Luthier, N. F. de Rooij, P. Renaud, Low-cost technology for multilayer electroplated parts using laminated dry film resist, Sensors and Actuators A: Physical 53 (1) (1996) 364-368.

[55] E. Kukharenka, M. Farooqui, L. Grigore, M. Kraft, N. Hollinshead, Electroplating moulds using dry film thick negative photoresist, Journal of Micromechanics and Microengineering 13 (4) (2003) S67.

[56] P. Walker, W. H. Tarn, CRC handbook of metal etchants, CRC press, 1990.

[57] F. A. Lowenheim (Ed.), Modern Electroplating, John Wiley and Sons, 1963.

[58] I. Papautsky, B. K. Gale, S. K. Mohanty, T. A. Ameel, A. B. Frazier, Effects of rectangular microchannel aspect ratio on laminar friction constant, in: Symposium on Micromachining and Microfabrication, International Society for Optics and Photonics, 147-158, 1999.

[59] S. Gong, P. Cheng, A lattice Boltzmann method for simulation of liquid-- 
774 vapor phase-change heat transfer, International Journal of Heat and $775 \quad$ Mass Transfer 55 (17) (2012) 4923-4927.

776 [60] R. Basit, M. A. Basit, Simulation of phase separation process using 777 lattice Boltzmann method, Can. J. Comput. Math. Nat. Sci. Eng. Med $778 \quad 1(3)(2010) 71 Y 76$.

779 [61] 3M, 3M ${ }^{\circledR}$ Novec $^{T M} 7200$ Engineered Fluid, original document from $3 \mathrm{M}^{\circledR}$ 780 Electronics Markets Materials Division, 2009.

781

782

[62] S. Gong, P. Cheng, Numerical investigation of droplet motion and coalescence by an improved lattice Boltzmann model for phase transitions and multiphase flows, Computers \& Fluids 53 (2012) 93-104.

[63] P. Cheng, H. Wu, Mesoscale and microscale phase-change heat transfer, Advances in heat transfer 39 (2006) 461-563. 